\title{
Resilience in the Mountains: Exploring the Labor and Motives of Food-Caregiver Women Repairing Broken Food Systems in West Virginia Communities
}

\author{
Heidi Lynn Gum \\ West Virginia University, hlgum@mix.wvu.edu
}

Follow this and additional works at: https://researchrepository.wvu.edu/etd

Part of the Appalachian Studies Commons, Food Studies Commons, Human Geography Commons, and the Women's Studies Commons

\section{Recommended Citation}

Gum, Heidi Lynn, "Resilience in the Mountains: Exploring the Labor and Motives of Food-Caregiver Women Repairing Broken Food Systems in West Virginia Communities" (2020). Graduate Theses, Dissertations, and Problem Reports. 7692.

https://researchrepository.wvu.edu/etd/7692

This Thesis is protected by copyright and/or related rights. It has been brought to you by the The Research Repository @ WVU with permission from the rights-holder(s). You are free to use this Thesis in any way that is permitted by the copyright and related rights legislation that applies to your use. For other uses you must obtain permission from the rights-holder(s) directly, unless additional rights are indicated by a Creative Commons license in the record and/ or on the work itself. This Thesis has been accepted for inclusion in WVU Graduate Theses, Dissertations, and Problem Reports collection by an authorized administrator of The Research Repository @ WVU. For more information, please contact researchrepository@mail.wvu.edu. 


\title{
Resilience in the Mountains: Exploring the Labor and Motives of Food-Caregiver Women Repairing Broken Food Systems in West Virginia Communities
}

\author{
Heidi Gum \\ Thesis submitted to the Eberly College of Arts and Sciences \\ at West Virginia University \\ in partial fulfillment of the requirements for the degree of \\ Master of Arts in \\ Geography \\ Cynthia Gorman, Ph.D., Chair \\ Bradley Wilson, Ph.D. \\ Jonathan Hall, Ph.D. \\ Department of Geology \& Geography
}

Morgantown, West Virginia

2020

Keywords: food justice, community food work, care work, labor, gender, race,

West Virginia, food system

Copyright 2020 Heidi Gum 


\begin{abstract}
Resilience in the Mountains: Exploring the Labor and Motives of Food-Caregiver Women Repairing Broken Food Systems in West Virginia Communities
\end{abstract}

\title{
Heidi Gum
}

Over the past four years the Food Justice Lab, now housed within the Center for Resilient Communities at West Virginia University, hosted a series of food access planning workshops across the state of West Virginia. Mobilizing more than 200 participants, the Nourishing Networks workshop training program was designed to build grassroots capacity for food system change. Eighty-percent of workshop participants were women and dialogues recorded at these events revealed how women are disproportionately impacted by food insecurity and disproportionately labor to repair a broken food system. Women in West Virginia are not only growing food, feeding their families, selling it at the grocery stores, serving it in restaurants and schools, and distributing it in food pantries, they are organizing for policy change in their own communities and working to combat systemic problems at the root of hunger and malnutrition. Absent from existing scholarship is an interrogation of the connection between community food work and the care work that goes into these labors of what I call food caregiver women. Furthermore, there is work to be done exploring the perspectives of these women through intersections of gender and race in the West Virginia context. In this research study, I explore the feeding and caregiving labors that 13 women in WV are performing through gathering their perspectives on their choice to do the work, the depoliticization and devaluation of it, as well as how their race and gender identities influence their experiences. In addition, I gather their visions of food justice and explore the capacities of their labors to create transformative food system change. 


\section{Acknowledgments}

This research study was inspired and made possible by the resilient and relentless women in West Virginia who pour their time, effort, love, and souls into their communities through efforts of care. I write this thesis during the global COVID-19 pandemic and witness daily how the very same women who took part in the study are now working overtime to address additional needs brought on by this time of crisis. I would like to express my gratitude to these women and others who inspired me, spoke with me, helped me, fed me, and trusted me during this research process. This is a product of your caregiving labor and my hope is that it sheds light on the crucial labor that you do to sustain West Virginia communities.

I would also like to express gratitude to my parents and sisters for a life where I felt privileged to grow food, hunt deer and squirrels, forage for ramps and mushrooms, and much more. It is because of my upbringing and the life we share that I have always felt a close relationship to food and nature. I am forever appreciative for your support and for believing in me throughout the years as I completed my education. It is an honor to be a first generation college student, and I hope I have made you all proud. This study is made possible in part by you all as well.

Lastly, I thank my advisor Dr. Cynthia Gorman and committee members Dr. Bradley Wilson and Dr. Jonathan Hall. Thank you for trusting me throughout this process and offering so much support in so many different forms. Each of you is a huge inspiration in this study and I look up to you all. Thank you to Densel Chapman for reminding me to take breaks and for cooking for me so often during the thesis writing process. I want to also thank Amanda Marple, Jed DeBruin, and Thomson Gross for being great friends and supporting me. Thank you all for

pitching in to purchase a Chromebook for me to write my thesis on. You have all contributed to making this research study possible. Thank you to everyone in the Center for Resilient Communities at WVU for being great co-conspirators and friends. Additional thanks to Martin Aucoin and Elizabeth Dever for your friendship and support as we learned how to survive as graduate students. 


\section{Table of Contents}

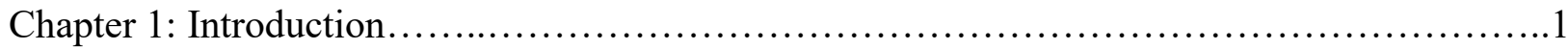

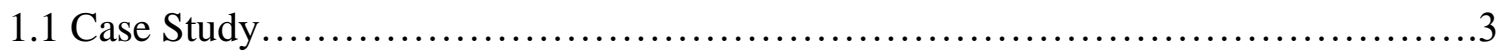

1.2 Research Purpose, Contributions, and Questions...............................6

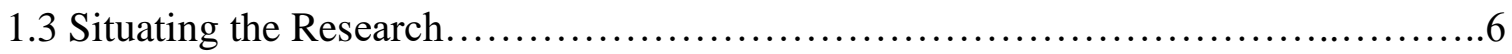

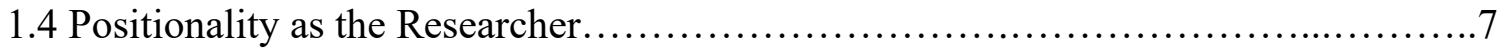

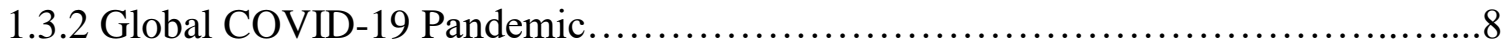

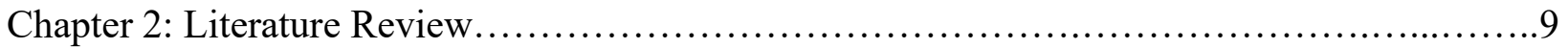

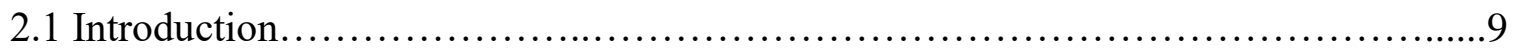

2.2 Community Food Security and Food Justice...................................10

2.3 Whiteness and Race in the Food System........................................

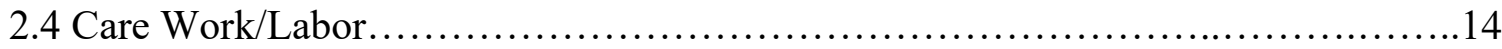

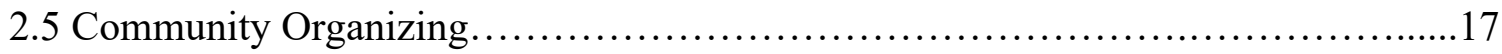

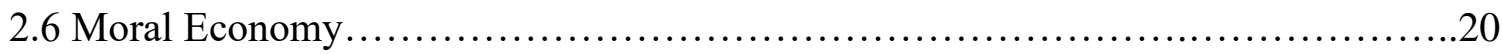

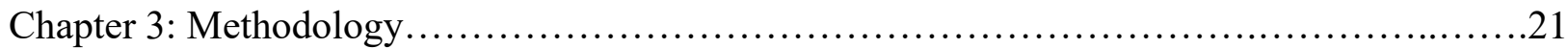

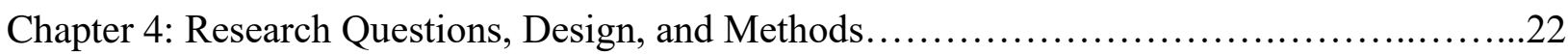

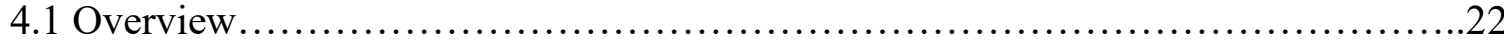

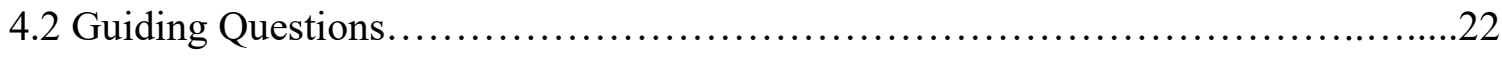

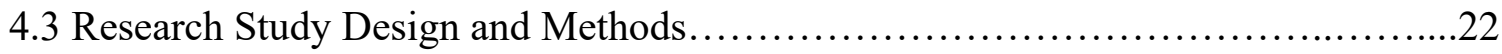

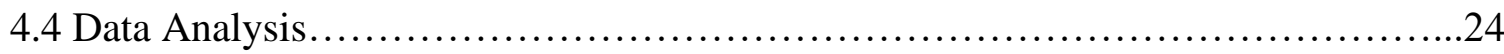

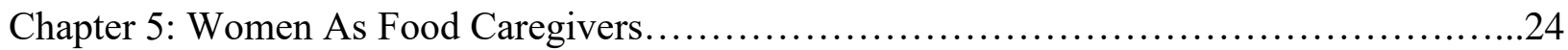

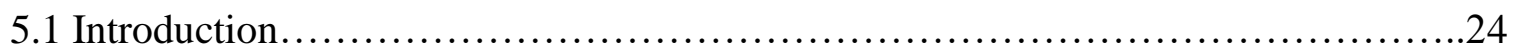

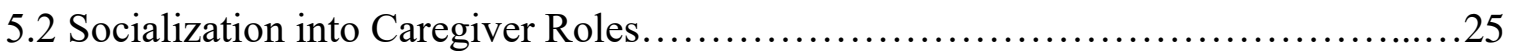

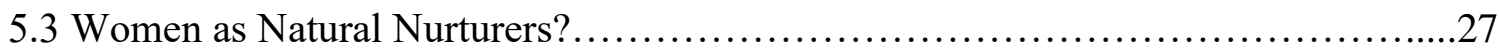

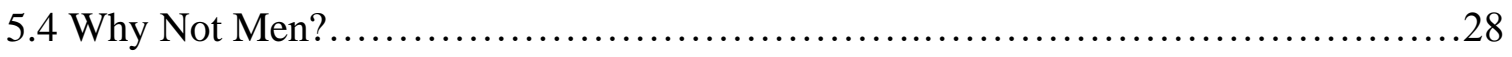

5.5 Devaluation of Women and Care Work......................................... 30

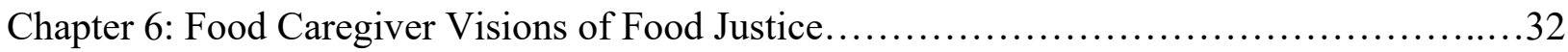

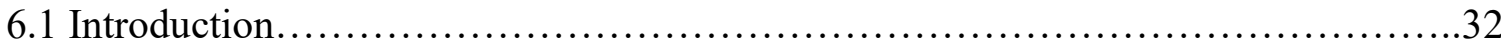

6.2 Food Justice in a Racialized Landscape ......................................... 33

6.3 Deconstructing Trauma by Creating Spaces for Learning and Healing...................35

6.4 The Importance of Conversation Around Race......................................37

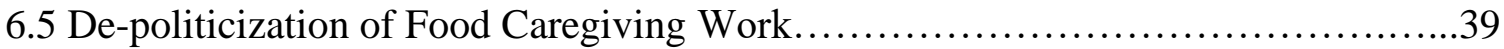

6.6 Patriarchal Culture and Extractive Ruins.........................................41

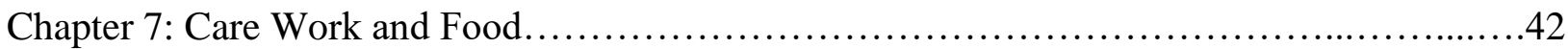

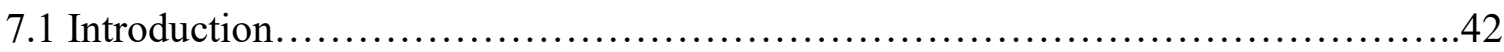

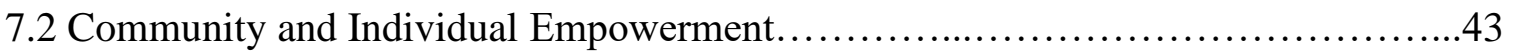

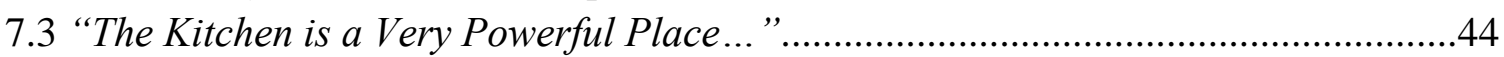

7.4 Listening and Conversation: Emotional Labor in the Work..........................45

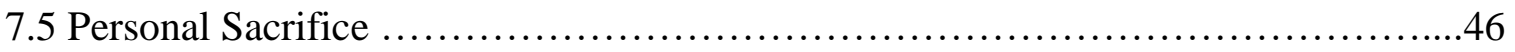


7.6 Genuine Concern and Care for People........................................ 46

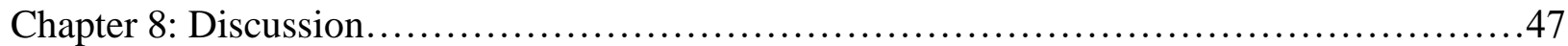

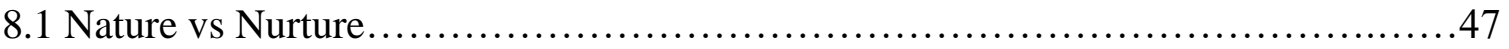

8.2 An Ethic of (Food) Caregiving ................................................ 48

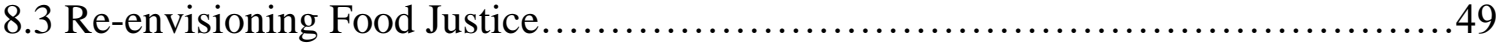

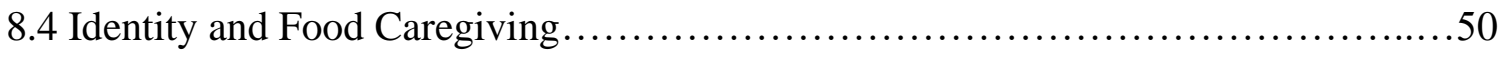

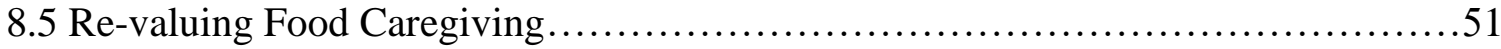

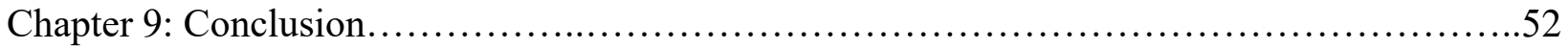

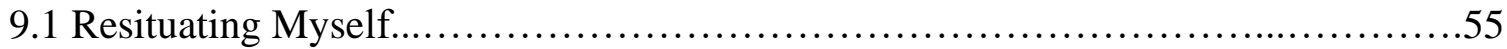

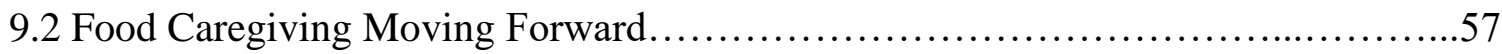

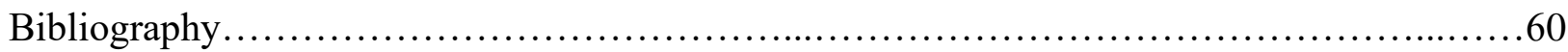

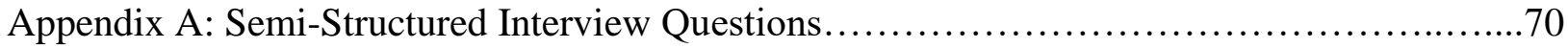

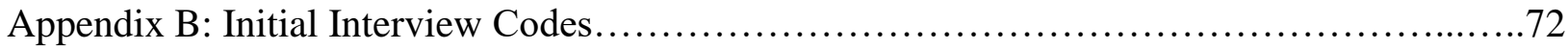

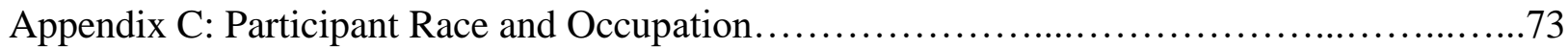




\section{Chapter 1: Introduction}

In 2018, a women-led teacher strike began in West Virginia during the month of February and lasted 10 days. The strike originated as an effort to raise wages for state employees and teachers and resulted in the shutdown of all public schools within the 55 counties of WV, therefore impacting some 250,000 enrolled students. Many food insecure students access the majority of their food while in school during the week through free and reduced breakfast and lunch programs. When schools shut down for 10 days, those 250,000 students lost access to the breakfast, lunch, and snacks that they typically had on a daily basis. This complication did not go unnoticed. As a response to this crisis, teachers and food pantry workers (predominantly women) collaborated in urgency at local charitable organization sites to organize the assembly of backpacks filled with nonperishable food that could be delivered to students during the strike. This sustained the strike - and it sustained the children. I stood on the frontlines during this political moment as one of the women assembling bags of food. In this moment I witnessed women working collaboratively, balancing caring for their communities and politically organizing for the welfare of their entire state. This historical moment remains an example of the feeding and caregiving labor that women are providing in WV communities and how that care is integral to political action. In a state where poverty and hunger is prominent, this becomes especially important.

In West Virginia, 1 in 7 people and 1 in 5 children struggle with hunger (Feeding America, 2019). Many communities and small towns in the region can be categorized as food deserts, or areas with limited access to affordable and nutritious food often due to a lack of grocery stores and influenced strongly by poverty (USDA, 2019). Many West Virginians struggle to survive and feed their families on a minimum wage of only $\$ 8.75$ per hour (NCSL, 2019). Rather than the result of personal failure, this food insecurity is the symptom of a failing capitalist food regime. Out of this failure, networks typically composed of women have emerged in West Virginia communities to tackle food access barriers and to feed and care for their communities. These types of labor, which can be categorized into state, charity, farming, selfprovisioning, and market driven efforts (Food Justice Lab, 2016), can be witnessed in the majority of food insecure communities. Even in counties where only one grocery store may be present and unemployment is high, resources such as food pantries, mobile farmers markets, 
school backpack programs, or charitable food box deliveries are organized and run disproportionately by women.

Many of these food access strategies and programs operate informally and are not well known by the public. The exhausting labors of women working to repair broken food systems in their communities is made invisible or intentionally devalued and depoliticized in society as well as in existing literature on care work and "food justice". Scholars often argue over which food access strategies qualify as "doing food justice work" and critique their capacity to create these systemic changes (Cadieux \& Slocum 2015; Alkon 2013; Mares \& Alkon 2011; Sbicca \& Myers 2016; Poppendeick 1998; Guthman 2008; Brown \& Getz 2008). Much community food work responds to more immediate rather than long-term need by providing food in the present moment through food pantries, congregate meals, farmers market, and the like. It thus remains contentious whether the food caregiving labor conducted by WV women, often falling into alternative food practice and charitable food categories, holds the potential to create long-term transformative food system change. Existing literature discounts community food work that results in short-term outcomes and meets immediate food insecurity needs (Alkon, 2013; Guthman 2008; Brown \& Getz 2008; Poppendieck 1998). However, the absence of these labors and strategies within their respective communities would unquestionably lead to more severe food insecurity crises. Indeed, they contribute greatly to meeting food access needs within communities despite their critiques. This research study addresses a gap in literature on community food work and care in rural Appalachia and explores the concept of "doing food justice" through the perspectives of the women on the ground engaging in the work.

Through my community food organizing work with Nourishing Networks, a food access workshop training program developed out of the Food Justice Lab at West Virginia University, I have seen women labor to repair a food system that fails families and communities through a lack of access to fresh, nutritious, culturally appropriate food. To address these failures, women are not only growing food, feeding their families, selling it at the grocery stores, serving it in restaurants and schools, and distributing it in food pantries, they are organizing their own communities and organizing for policy change to combat systemic problems at the root of hunger and malnutrition.

This research study explores women's leadership in community food systems through analysis of their labor, care work and advancing the right to food. My research draws from two 
years of action research with women leaders in West Virginia through my facilitation of the Nourishing Networks food access training program. Over the course of said two years, I trained and labored beside food caregivers, disproportionately women, and took note of the gendered and racialized dynamics of the labor. I seek to understand why women take on the role of "food caregivers," how this labor relates to women's work burdens, and how it advances the right to food through food justice organizing. I argue that the perspectives and experiences of food caregiver women challenge the exclusive boundaries of what constitutes "doing food justice work" as defined and critiqued in existing scholarship as mentioned above. In highlighting the labors of food caregiver women, I interrogate the capacity of their labor to create system food system change and be categorized as "doing food justice work". Moreover, these perspectives provide valuable data to assist in analyzing whether these firsthand accounts of community food work call for an expansion of what constitutes doing food justice work.

\subsection{Case Study}

Nourishing Networks is a healthy food access planning and training workshop program developed in the Food Justice Laboratory, housed in the Center for Resilient Communities at West Virginia University. This workshop-based training program is designed to raise up human resources as they build grassroots capacity for food system change. It aims to create a network of community members that can identify food access barriers existing in communities, determine assets that can be leveraged to combat the barriers, and build more equitable food systems by use of collaborative action and community level strategizing. From 2016-2018, the Food Justice Laboratory organized a series of 6 pilot Nourishing Networks workshops across the mountain state in Wayne, Fayette, Logan, Calhoun, Wetzel, and Wood Counties with a total of over 200 participants. For methodology, the workshops used small focus groups of 4-7 people all engaging in various sectors of the food system. These focus groups included people working in all areas of the food system including state and government entities and assistance, charitable assistance, farming, self-provisioning, and food retail markets. Within workshops, participants identified food access barriers in their county, identified assets to be leveraged to combat barriers, and then created strategies to be implemented within their communities. In addition to organizing community food work, participants were simultaneously being trained to act as 
facilitators across the state to later implement these workshops in their own more localized communities and neighborhoods.

This research study is inspired by 2 years of action research conducted in the Food Justice Lab at West Virginia University during the implementation of the Nourishing Networks Program. As described above, this action research program consisted of 6 food access planning workshops that I coordinated, acted as a facilitator in, and examined and explored findings alongside fellow food justice lab members. Through this experimentative and explorative work, I noted prevalent gender dynamics within workshops and West Virginia food systems. Not only are women disproportionately impacted by food insecurity and poverty, but $80 \%$ of workshop attendees (roughly 225 total) were women who directly work in WV food systems in some capacity. Of the action teams that resulted from the workshops to implement strategies, $100 \%$ were women. These networks of women who attended workshops and implemented the strategies that were created in the workshop process consisted of food pantry and food bank personnel, producers, nutrition and health educators, public health workers, and more. Through engaging directly with these networks of women, I noted not only gendered dynamics on the work, but also the seemingly omnipresent whiteness in West Virginia food systems. Most workshop attendees were white women serving largely white communities. Following completion of the 6 workshops, I was left with many questions about food justice in community food work, gendered experiences, racialized experiences, and the relationship between care and food.

To seek answers to my questions and explore perspectives of these food caregiver women, I organized and facilitated this qualitative research study. Between the months of January-March 2020, interviews were conducted with 13 food caregiver women who are involved in community food work in West Virginia in some capacity (See table below for information on participant racial identities and occupation within the food system). 


\begin{tabular}{|l|l|l|}
\hline Participant & Racial Identity & $\begin{array}{l}\text { Food System Sector/Work } \\
\text { Focus }\end{array}$ \\
\hline Participant 1 & White & Advocacy/Organizing \\
\hline Participant 2 & White & $\begin{array}{l}\text { Public Health/University } \\
\text { Extension Education }\end{array}$ \\
\hline Participant 3 & White & $\begin{array}{l}\text { Charitable Food - Food } \\
\text { Pantry }\end{array}$ \\
\hline Participant 4 & White & $\begin{array}{l}\text { University Extension } \\
\text { Education }\end{array}$ \\
\hline Participant 5 & African American & Community Development \\
\hline Participant 6 & White & Agriculture/Policy \\
\hline Participant 7 & White & Agriculture/Policy \\
\hline Participant 8 & White & Agriculture - Producer \\
\hline Participant 9 & White & Charitable Food - Food Bank \\
\hline Participant 10 & Black & Organizing/Policy \\
\hline Participant 11 & Black & Policy/Organizing/Education \\
\hline Participant 12 & White & Education/Research \\
\hline Participant 13 & Biracial - South & $\begin{array}{l}\text { Education/Public } \\
\text { Health/Research }\end{array}$ \\
\hline
\end{tabular}

Table listed in Appendix $C$

Of the 13 interviews, one was conducted in person at the informant's choice and the others were conducted over the phone. West Virginia was chosen as a geographic location for this research study as it is inspired by 2 years of prior experience working alongside food caregiver women in the state. Food caregiver women who take part in this study consist of both women who attended Nourishing Networks workshops and those outside of the workshop process who also labor in West Virginia food systems through engaging in community food work in the state (See participant selection process in Section 4.3). 
1.2 Research Purpose, Contributions, and Questions

Guiding Questions of the Study:

1. How do West Virginian women working in the food system (food caregivers) understand and describe the relationship between food and care work?

2. How do food caregiver women understand their work in relation to the concept of food justice? Furthermore, do their perspectives call for an expansion of what constitutes doing food justice?

3. How do food caregiver women laboring in the various sectors of their food systems describe the motives and rationale behind providing caregiving and feeding labor in WV communities?

4. How do food caregiver women perceive the role of their identity, particularly gender, in their work in relation to community organizing for food security?

5. How food caregiver women describe the role of morality and societal expectations regarding caring for their communities and their work to create a more equitable food system?

6. How do food caregiver women describe why the majority of the crucial caregiving labor in WV food systems performed by women?

\subsection{Situating the Research}

In this study I explore the labor of what I call "food-caregiver" women in rural, food insecure West Virginia communities. I interrogate the common critique of much community food work lacking capacity to create any broader systemic change in the food system. Through semi-structured interviews with key informants, I have gained perspective on how food caregiver women perceive their labors in terms of transformative potential by asking if these women consider themselves to be "doing food justice" in their work. Women have tended to strategize using a variety of tactics in the wake of failures of capitalist food regimes that operate in their communities. As Feminist standpoint theorists argue, the women participating in this research study are the best equipped to describe their standpoints and the aspects of their labors (Harding, 1986; Hartsock, 2004; Collins, 1995; Collins 2006). Women performing the care-repair work in 
their communities are the ones to best describe the nature and capacities of their labor. Furthermore, they are best situated to describe the difficulties of their work as well as the oppression they are working against through their work. Food caregiver women can offer a firsthand account of failures of the food system and the viability of their labors to address these failures. Women who have attended the workshops have often identified under similar race, age, and class demographics with the majority with most being middle-aged white women. Their own perspectives of what care their communities need and how they pinpoint the main barriers to healthy food access in their communities is unique to them based on their intimate experiences engaging in this work and with other citizens in their service areas.

Even if this work is not perceived as transformative justice work by the women who perform it, it is still important for rural WV communities. Furthermore, it is not sufficiently valued in society (Charles \& Kerr 1988). Again, the devaluation of this work makes it seem like it must be easy, however preliminary work has shown that it is exhausting and emotionally draining labor often carried out by people who identify as food insecure themselves. This work done in rural WV communities by women - be it motivated by societal pressure, compassion, anger, fear, or otherwise - is vital. So then, what are the motivations and rationale behind this work? This research study provided the opportunity to ask these questions while interrogating capacities and bandwidth of the work.

\subsection{Positionality as the Researcher}

I have conducted background research through my role in the Nourishing Networks food access planning workshops in the WV counties of Wayne, Fayette, Logan, Calhoun, Wetzel, and Wood. Research participants include women workshop attendees as well as collaborators from partner organizations and those I have met through my work in the Food Justice Lab and Center for Resilient Communities.

In each county, the Food Justice Lab partnered with organizations to move the strategies forward that resulted from and were outcomes of the workshops. This support and accompaniment took place in various forms and included but was not limited to organizing community meetings, picking up and dropping off produce for markets, speaking at events facilitated by partner organizations, handing out charitable food boxes to seniors, managing transactions at a farmers market, providing technical assistance, and working to get SNAP/EBT 
accepted at farmers markets or other events. Support and accompaniment of projects as well as collective action and commitment towards a common goal led to a relationship of trust being built between the Food Justice Lab and these partner organizations as well as between myself and several research participants involved in this study. This affected my research process in terms of the willingness of participants to engage in the interviewing process and to share information on their experiences, motivations, and the rationale behind their labors.

My positionality, as every researcher's does, continued to influence my research throughout the entire research process and affects how it is conceptualized, executed, interpreted, represented, and distributed. Chaves (2008) describes what he defines as "insider scholars" who are either total insiders, in which the researcher shares multiple identities (e.g., race, ethnicity, class) or experiences; or partial insiders, who share a single identity (or a few identities) with a degree of distance or detachment from the community. In this research study, I identify as a partial insider. Like some of my research participants, I identify as a white West Virginian woman from a low to lower middle class background, who labors toward food security in West Virginia food systems. I believe that some shared identities granted me even more trust with research participants based on potential similarities in my own labors and experiences. However, my institutional position as a graduate research assistant in academia may offer an identity that most participants did not identify with. Additionally, as a white researcher asking questions about whiteness and race, it should be noted that because several participants identified as other races, this too may have affected the level of trust and comfort that participants experienced in discussing topics with me, and this shaped how interviews evolved.

A partial insider experience allowed me to converse on a deeper level regarding certain topics. I too live the experience of being a white woman performing food caregiver labor in WV food systems (although this of course is experienced differently by others) and I have my own experiences, motives, and rationale for doing so. I find that this has been incredibly valuable to my research. As Chavez (2008) states, "Insiders can understand the cognitive, emotional, and/or psychological precepts of participants as well as possess a more profound knowledge of the historical and practical happenings of the field” (pg. 475). As a result, I have formed closer relationships and friendships with a few various participants. I make note of this because I believe it highlights the importance of storytelling and listening. These friendships may seem informal, but they will inevitably affect my future working relationships with these women. 
Through this research study, I found that collaborative working relationships were strengthened, and deeper trust was formed. I engaged more on a more personal level with several of my informants following the research process.

\section{$\underline{1.5 \text { COVID-19 Global Pandemic }}$}

Near the end of conducting interviews with research participants, the 2019 global COVID-19 pandemic became more severe and many people began quarantining in their homes as advised by the governor of West Virginia. Many people began adjusting to this very unique situation and had to work from home, take on childcare full time, and care for others. As a result of these sudden and vast changes, it became slightly more difficult to keep in touch with potential research participants that had yet to schedule an interview. Because of this, I was able to recruit a few less participants for interviews than planned. Other than ending up with 13 rather than the initially planned $15+$ interviewees, conducting this study within the context of the coronavirus pandemic did not affect the study.

Although most interviews had been conducted before the pandemic became more serious, it was still interesting to witness how the labor of study participants and other food caregiver women in the state adjusted to the conditions and work even harder to address needs. At the time of writing this thesis post-conducting research and currently living during a global pandemic, I witness woman farmers strategizing to do produce pick-ups, I see pantry and food bank workers working double time, and I notice Extension agents working double time to get seeds and educational materials relevant to the pandemic into WV homes. These workers are more essential than ever, and I am experiencing a new historical moment where food caregiver women in the state work to address needs in times of crisis and hold together communities through it all.

\section{Chapter 2: Literature Review}

\section{$\underline{2.1 \text { Introduction }}$}

The areas of literature I engage with in my research include: 1.) Food Justice and Community Food Security, 2.) Whiteness and Racism in the Food System; 3.) Care Work/Labor, 4.) Community Organizing, and 5.) Moral Economy. An understanding of the food justice framework has served as an important starting point. In latter chapters I will interrogate whether caregiving labor qualifies as transformative justice work according to women who are doing this 
work in West Virginia. Using relevant scholarship, I have explored how my research participants perceive their work through this framework. Because race touches every part of human society including the food system, whiteness and racism in the food system are also explored. Likewise, an understanding of literature around community food security has been crucial as it is what most food system organizers, whether they are claiming to be doing food justice work or not, are laboring towards in their efforts. Care work and labor literature underpins my research and embodies the labors that primarily women are performing in West Virginia and that are examined in this study. Community Organizing provides the tools to understand how and why these women are organizing their communities toward food security. Lastly, literature on moral economy is explored given that one of my aims has been to better understand the motivations for beginning and continuing these caregiving labors.

\subsection{Community Food Security and Food Justice}

Community food work can be described as a framework for making sense of the interconnections and complexities of food system issues such as farm sustainability, food access, health equity, environmental resilience, and social justice (Ligrani \& Niewolny, 2017). Slocum (2006) builds on this definition to describe community food work as food systems work that promotes fair prices, sustainable practices, and accessible, affordable, culturally appropriate, and healthy food for all people. A large sector of community food work includes efforts towards increasing community food security where hunger is present. The women I have met during Nourishing Networks come to the table with a diversity of these narratives (healthy food, affordable food, sustainable practices, etc.) shaping their aims, and this often is manifested through work such as nutrition education, charitable food, and farming education.

In the context of rural food insecure West Virginia communities, networks of women can typically be found laboring in communities as food pantry directors, WVU Extension nutrition and agriculture educators, food bank personnel, and more. Though these women may have very different job titles, roles, and motivations, the ultimate goal is essentially to care for their communities by increasing community food security where they live and work. These labors are all efforts toward community food security. According to Fisher (1997), community food security was first conceptualized in 1994 by a broad coalition of advocates seeking comprehensive solutions to the nation's food and farming crises. It is a multifaceted concept that 
includes intersections between not only communities, but the 1) environment, 2) economy, and 3) culture of a region. Fisher (1997) also identifies 5 major principles of the community food security movement: 1) needs of low-income people, 2) community focus, 3 ) selfreliance/empowerment, 4) local agriculture, and 5) food systems. Perhaps missing from these intersections and principles is the intersection of race, which this study has sought to explore within the perspectives of food caregiver women.

Many strategies and tactics that communities leverage in their efforts to increase community food security are often critiqued as being neoliberal in approach and lacking any potential to create sustainable or systemic, structural changes within a food system (Broad, 2016). Neoliberalism is a political economic philosophy which claims that human well-being can best be achieved if the free market is to operate with little to no intervention from the state (Harvey 2005: 2). Just as it is difficult to put food justice principles into practice, many people laboring in food justice work reflect aspects of neoliberalism, yet projects and practices seem to model it (Harrison 2008; Guthman 2008; Allen 2008; Brown and Getz 2008). These food justice and neoliberalism critiques are interrelated as strategies pursued through the market, such as starting a business or buying particular kinds of goods, are by definition less accessible to lowincome people. In other words, no form of long-term social justice is necessarily taking place in many of these efforts according to many. For example, lots of food caregiver women are working for charitable food agencies, perhaps the most commonly critiqued sector in food system work. Labors that can create larger, systemic change are often described using the term "food justice".

Food justice is described as a transformation of the current food system, including but not limited to eliminating disparities and inequities (Gottlieb and Joshi, 2010). The Institute of Agriculture and Trade Policy (IATP) (2019) defines food justice a bit more detailed as "The right of communities everywhere to produce, process, distribute, access, and eat good food regardless of race, class, gender, ethnicity, citizenship, ability, religion, or community." This study aims to explore what labor constitutes "doing food justice" work, and if community food work can foster transformative change from the perspective of women who labor in this system. Broad (2016) poses that there are certain criteria that must be met in order for community food security efforts to be sustained over time to increase "food justice": 1) ongoing participation, 2) committed vision for systemic change, 3) plan for programmatic sustainability, and 4) and ability 
to have influence beyond solely the local. My research explores how food caregiver women perceive their work through these frameworks of food justice.

It is also important to note that while many scholars and organizers use a framework of justice, it is much more difficult to put those principles into practice. This is especially true considering there is no universally accepted definition of food justice. Furthermore, what is considered "just" is likely to vary vastly depending on who you ask in the world and what their experience is like. Women have tended to strategize to feed communities using non-capitalist strategies rather than market-based approaches in the wake of failures of capitalist food regimes that operate in their communities, such as charitable food and alternative food practices. This research study has provided an opportunity to seek answers to these types of questions through speaking to these women who are on the ground performing these labors and experts at feeding their communities. Scholarship on what constitutes food justice may be limited and exclusionary if it relies on assumptions about gender and labor. I argue that the perspectives of the women often left out of this scholarship expands the definition of "food justice work" to include labor which I define as "food caregiving”.

\subsection{Whiteness and Racism in the Food System}

Garner (2007) describes whiteness as a system of privilege and social tool used to bolster white supremacy, set hierarchies, and create societal norms. Whiteness privileges white people and classifies them as 'unmarked' or 'normal', invisibilizing white as a racial category (Garner 2007). Because of this, white people have the power to create hegemonic ideas within society, whether they recognize it or not. When being white is considered 'normal', those who benefit from whiteness often are unable to recognize it, especially in areas where the population is predominantly white - as is true for much of the state of West Virginia. Literature on race and the construction of whiteness has its origins in the works of W.E.B. Du Bois (1920), James Baldwin (1963), Theodore W. Allen (1976), Angela Davis (1983), Toni Morrison (1992) and Ruth Frankenburg (1993) among others. The social phenomena of whiteness can be witnessed in all aspects of society in the US, including the food system where whites clearly benefit in ways where other racial groups experience disparities and racism (Slocum 2007; Alkon \& McCullen 2011; Guthman 2008; McCutcheon 2011; Reese 2019). Saldhana (2006) describes how each stage of food within the food system (how it is produced, packaged, distributed, priced, etc.) is 
racialized and a white, middle class consumer base is prioritized within all decision making based on these factors. Moreover, sustained leadership of white people in the food system grants them power and privilege, creating a cyclical nature in which these racial disparities are able to continue. Race is deeply embedded within our food system, and it touches every part of it from field to fork (Billings and Cabbil 2011). If food justice work is to work towards some genuine type of justice or transformational change, the acknowledgment of these facts is crucial (Alkon \& Agyeman 2011).

However, simply acknowledging whiteness within the food system and even within food justice work is not sufficient. To move toward a more equitable and just food system, those engaging in the work need to move beyond neoliberal and raced strategies that do little to actually create change through dismantling racism and white supremacy in the food system (McCutcheon 2019; White 2011; Passidomo 2013; Slocum 2006; Alkon \& Mares 2012; Morales 2011; Norgaard et. al. 2011; Ramirez 2015; Reese 2019; Slocum \& Saldanha 2016; Sbicca 2012). Incorporating anti-racist practices into community food work is critical yet does not seem to materialize sufficiently when it is time to put words into action.

In a study exploring racial equity within food justice organizations in the U.S., Hislop (2007) found that less than $20 \%$ of the organizations had policies that required community participation. Of those in leadership positions, less than $30 \%$ were people of color. Only $17 \%$ of organizations indicated that formal discussions on race and socioeconomic disparities in the work take place (Hislop 2007). People of color have historically been underserved and underrepresented in a country built on slavery and land theft (Billings \& Cabbil 2011; HoltGiménez 2014). If a more just food system is to be fostered, then those who are most impacted by food insecurity, namely women and people of color, need to occupy leadership positions which give them decision making power within the food system and on issues that directly affect them and those of similar identities who have been kept out of conversations before (Lee et.al. 2009). Slocum (2006) advises that community food organizations actively consider that the U.S. food system was built on foundations of genocide, slavery, and institutions that have dispossessed racialized groups of cultural pride, land, and wealth in both gender and classspecific ways. Furthermore, the incorporation of anti-racist practices and trainings are pivotal in dismantling current racist structures of the food system (Slocum 2006). 


\subsection{Care Work/Labor}

Folbre (2003) describes care work as work that involves connecting people to one another, trying to aid people in meeting their needs, teaching, and caring for the children, elderly, and those that are ill. Care can be provided in endless ways. According to Abel \& Nelson (1990), "Caregiving is an activity encompassing both instrumental tasks and affective relations... caregivers are expected to provide love as well as labor" (Pg. 4). Within this definition, implied within care are elements of love and intimate relationship. Many women that participated in Nourishing Networks have described their work in the food system as a "labor of love", and that "you have to really care about people" to be able to do it. Building on this, Cancian \& Oliker (2000) define caring as both feelings and actions that "provide responsively for an individual's personal needs or well-being, in a face-to-face relationship" (Pg. 2). Undoubtedly, this type of work is incredibly important and necessary for all humans. However, even the term "caregiver" can be incomplete in definition. As Meyer, Herd \& Michel, argue, this term itself has the potential to ignore how caregivers, often women, tend to offer substantial amounts of care in many forms at their own expense and with much personal sacrifice. The term "caregiver", used to describe one who performed care work, may have the implication that the care is offered freely, either at no cost or at a cost that the caregiver is able to willingly offer without sacrifice (Meyer, Herd \& Michel, 2000). There is some assumption of choice within the term "caregiver" when the term has connotations with love and relationships, but because the majority of people involved in this work are women, it is likely that gendered assumptions around who is responsible for providing this type of work are influential factors. As Makina (2009) states, "the fact that women do this work is connected to gender inequality: women still carry out most domestic work in the home and community, and female children continue to be socialised into the role of carer" (Pg. 335). For example, as toddlers, many girls are given baby dolls and kitchen sets because these are the toys marketed to young girls. This research study aims to explore the motivations and rationale behind doing this work and further explore how food caregivers describe the role of "choice" and societal expectations in performing these labors.

Paula England (2005) identifies and describes 5 emerging theoretical frameworks on care work. These frameworks provide a way to understand the differing reasons women are expected to or choose to provide care labor and why their care work may be perceived in particular ways. First, the "devaluation" perspective argues that care work is badly rewarded because care is 
associated with women - often women of color (pg. 382). The "public good" framework points out that care work provides benefits far beyond those to the direct recipient and suggests that the low pay of care work is due to a failure of markets to reward public goods (pg. 385). The "prisoner of love" framework argues that the intrinsic caring motives of care workers allow employers to more easily get away with paying care workers less (pg. 389). The fourth "commodification of emotion" framework focuses on emotional harm to workers when they have to sell services that use an intimate part of themselves (pg. 391). Lastly, the "love and money" framework argues against assumptions that markets are inherently selfish and corrupt in nature and that nonprofit and informal work is generally unselfish and genuine (pg. 393). I especially make use of the devaluation framework in exploring the motivations for feeding as care work. Indeed, many of these frameworks can be applied to the rationale behind the labors of my research participants, specifically in an intersecting manner.

Globally, care work is typically provided by women both inside and outside of the home. According to a report from the International Labor Organization, women perform $76.2 \%$ of total hours of unpaid care work worldwide, which equates to more than three times as much as men (ILO, 2018). Cultural and social ideas devalue women and thus, by cognitive association, devalue care work which is typically done by women. Simply put, female-dominated jobs involving care are especially devalued because performing care is a quintessentially constructed as female/feminine identified activity or labor and thus inferior (Cancian \& Oliker 2000, England \& Folbre 1999, England et al. 2002; England 2005; Makina 2009, Elson 2017).

This devaluation of care work is compounded when gender is understood as intersecting with race, class, and immigration status. For example, many white women who perform paid care work possess a college degree, whereas care work which does not require a college degree (and is therefore typically lower-wage) is performed more often by immigrants and women of color (Hondagneu-Sotelo 2001; Misra 2003; Romero 1992). For immigrant women, even if they have a college degree, they may be relegated to devalued work because of the gender-racialized nature of the labor market (ex. The "maid-trade"). Race shapes the types of care work women are performing, where they perform this labor, and how (if) it is valued. Many scholars have also written about the disproportionate burden on women of color for providing care to children, the elderly, and communities other than their own, as well as the transnational network of care that have emerged to service the needs of wealthier countries in the global north (Collins 2000; Pratt 
2013; James 1993). My interviewing of both white women and women of color has helped to identify some key differences between approaches of food caregiving labor with intersections of gender and race.

Historically, the social relations around food have been organized along the lines of gender, and women tend to bear the responsibility of provisioning food for their families and communities (Allen \& Sachs 2012). Allen and Sachs (2012) describe food provisioning as the most basic labor of care work. Within the initial Nourishing Networks workshops facilitated by the Food Justice Lab, roughly $85 \%$ of all attendees were women. Of the action teams or "networks" that carried the food access strategies forward following the workshops, 100\% were women. These women are provisioning food for their communities in different ways, from assembling food pantry boxes, to helping citizens apply for the Supplemental Nutrition Assistance Program (SNAP) and the Women, Infants and Children (WIC) program, to growing food to be sold to the local public.

Important to acknowledge here is that women are not biologically or naturally inclined to perform care work. In her essay on performative acts and gender constitution, Judith Butler (1988) describes how gender is constituted in the mundane acts of the body - that performative acts are what constitutes gender. Butler (1988) reminds us of the famous quote from Simone de Beauvoir, "One is not born, but rather becomes a woman" (Pg. 519). In other words, she proposes here that gender is not a starting place for humans. Rather, she describes it as an identity repeatedly constructed through time and constructed through the body. This is especially true in the context of women bearing the responsibility of feeding their families and communities. Makina (2006) notes that women socialization into caregiving labor emerges from social and contractual obligations associated with marriage or other family relationships. She states, "Gender relations in sub Saharan Africa, and elsewhere, is still only partly recognised. The fact that women do this work is connected to gender inequality: women still carry out most domestic work in the home and community, and female children continue to be socialised into the role of carer" (Pg. 310).

Because this socialization begins at such a young age, it is often not even recognized as being as such. Rather, it may simply seem as though women performing care is just the way things are meant to be and how society is to function. It becomes so normalized that many do not question it, or even begin to believe that women are simply more naturally inclined or better able 
to perform the labor. Butler (1988) states that while we are performing, we oftentimes do not even realize that we have formed a belief about our gender. We see gender as a natural occurrence and forget that it is naturalized through performance. The idea that women carry some sort of natural capacity or innate desire to provide caregiving labor for others reifies the notion of sex difference and bolsters gender inequality by burdening women with responsibility for this labor and justifying their employment in low paid care work positions (Meyer 2000; Makina 2006).

Much of the work that I have witnessed women doing in West Virginia food systems mirrors the types of tasks that mothers are typically imagined or expected to be performing in the home (E.g. cooking meals, providing groceries for others, packing backpacks, providing elderly and childcare, etc.). The difference here is of course that women are performing this not only for their own children and families, but also for the children of others and communities at large. Naples (1992) in describing what she calls "activist mothering" states that the practice of activist mothering not only involves nurturing work for those outside one's kinship group but also encompasses a broad definition of actual mothering practices. This term "activist mothering" perhaps can re-politicize these caregiving labors, and I argue this is rightfully so. This study not only examines the reasons that women choose to engage in this work, and perhaps unearths reasons for overrepresentation of women providing food caregiving labor, but also explores the political and transformative nature of the labors.

\section{$\underline{2.5 \text { Community Organizing }}$}

Community organizing is a method of engaging and empowering people with the purpose of increasing the influence of groups that have been historically underrepresented in policies and decision making that affects their lives (Gittel \& Vidal, 2013). In community organizing, members of communities are organized to act collectively on their shared interests. Community organizing is often a place-based activity, used in low-income and minority neighborhoods where economic or social disparities are present. This is especially important in the context of Appalachia and West Virginia where there is a long history of people living in the area and exerting little control over powerful extractive industry. This organizing is also used among common interest-based "communities" of people, such as new immigrant groups, who have limited participation and influence in decision making that affects their lives (Gittel \& Vidal, 
2013). Indeed, in the context of West Virginia, a legacy from the coal industry lives on and in part contributed to poverty, unemployment, low job opportunity. These are major factors that foster food insecurity.

This research study examines the activism and caring labor that rural West Virginian women are performing to support communities - but this is no groundbreaking development. Throughout history women have not only participated in, but also led and initiated rebellions to care for and defend the welfare of their family, community, class, race, or ethnic group (Mikula, 2005; Wilkerson, 2019). Although these women-led labors are often devalued and depoliticized in society and absent in scholarship, they have existed historically as well as in the present day. Indeed, I argue that women tend to organize in different ways than men in terms of feeding communities, and the care and activism that the women in my study execute is both nurturing and empowering, while simultaneously confrontational and competitive. Martin (2010) makes the argument, "Indeed, the very idea of distinct styles and concerns for women's and men's community organizing essentializes the contributions of women and men into dichotomies of 'masculine'-confrontational and competitive - and 'feminine' - nurturing and empowering".

In 'To Live Here, You Have to Fight', Wilkerson (2019) takes us through a series of accounts of white Appalachian women as community leaders and women-led activist groups making waves in the Appalachian region in the 1960s and 1970s and draws attention to this backbone of support that women both historically and presently provide in their communities. Wilkerson develops the concept of an "ethic of care" as resistance, which brings attention to how the efforts of women as caregivers aimed to transform their communities. The concept of “caring" manifests itself as central to fairness and justice, as well as to rights and democracy (pg. 198). Wilkerson states, "The women activists of this history tended to the broken bodies of miners, mourned the dead, raised children, fought for clean water, fed the families of striking workers, carried their neighbors to hospitals, helped relatives navigate welfare offices, implemented school lunch programs, distributed educational resources, sheltered abused women, fought for parental leave, and much more” (pg. 197). Several of these historical acts of care involved feeding, and in present times women in WV are fighting for the same rights for their communities in the legacies of poverty and food insecurity that the coal industry has left behind. 
Through a focus on the "caregiving" motives of Eastern Kentucky women, Wilkerson (2019) identifies the ways in which women used their societal role as nurturers in their communities to fight for anti-poverty funding, black and white civil rights, the poor people's campaign, labor rights for miners, welfare rights, gender equality, and women's health issues. Many parallels can be drawn here between these eastern Kentucky women and food caregiving women in West Virginia - who are nurturers in an explicitly nutrition and health-focused sense. Wilkerson challenges the dominant theme of historical accounts that focus primarily on male figures, and gives voices to the women who made history in their everyday lives by challenging capitalism, patriarchy, classism, and the war on poverty in a region with a past saturated with extractive industry and economic downturn. Through highlighting the role of these women's monumental and largely unaccounted for efforts, Wilkerson exposes the value of caregiving labor in grassroots efforts that made Appalachian communities safer, healthier, and more equitable places to live. Wilkerson underscores how many of the women in her stories were taking risks by striking, picketing, and organizing, all the while carrying the burden of domestic labor in their homes. Careful not to essentialize or romanticize, she generates a new portrait of the white Appalachian woman, one that is tenacious, mighty, and resourceful. Scholarship on West Virginian women who feed communities remains under-researched, which leaves fertile grounds to generate a portrait of how these people work tirelessly to keep their communities nourished and how their experiences and perspectives may differ from others.

The political nature of care work and food provisioning is a recurring theme in other research on Appalachian organizing. Ansley and Sessions (2009) offer another inspiring example of crucial caregiving labors of women during a miner strike in Kentucky by describing the efforts of Jean, a miner's wife, "I know of Jean because she is one of the many women who have invented a new kind of leadership in this strike ... she stands in my mind for all the women who took up the new challenges posed by the strike, who cooked biscuits, wrote poems, traveled to strange cities, met totally unexpected new friends from faraway places, who threw themselves into the strike for the sake of those who had gone before, for those who would come after, for their men in the mines, and for the exhilaration of feeling and using their own new powers" (pg. 220).

These are only a few examples of the caregiving labors that women provided in this context that held the community together and sustained the strike. Women are acknowledged at 
various points in the work of Ansley \& Sessions (2009) for the caregiving support they provide to communities in moments of crisis. Bake sales, soup kitchens, quilt raffles, singing groups, packing backpacks for miners, etc. are caregiving labors that are generally qualified as feminine. In reality, without money raised by fundraisers and food to provide energy, the strike would be unable to continue. However, because these labors are seen as typically performed by women, they are devalued and depoliticized. Baking biscuits, I argue, is a very political act when that bread becomes a resource for keeping people fed and healthy in order to sustain a strike. Furthermore, quilting raffles are political when the funds raised go directly into supporting the striking miners. These caregiving labors are crucial if a social or political movement such as this is to progress or be successful.

\subsection{Moral Economy}

The concept of a moral economy was first described by English historian E.P. Thompson who wrote of the moral economy of the poor in the context of widespread food riots in the English countryside in the late eighteenth century (Thomson, 1971). In this piece, Thomson describes these riots as overall peaceful acts that demonstrated a common political culture rooted in the right to set the price of essential goods in the market. In this case study, "fair price" was deemed more important to the community than a "free" market price. Large farmers selling their surpluses at higher prices outside the village while there were still those in need within the village was seen as unjust within the community (Thomson, 1971). As Götz (2015) explains, justice and balance are at the forefront of a "moral economy". More recently, Sayer (2016) defined a moral economy in simpler terms as an economy that takes into account a culture regarding the responsibilities and rights of individuals and institutions. It is generally accepted to mean an economy that is based on goodness, fairness, and justice. It is worth exploring the relationship between a capitalist food regime and economic system and how this translates into a moral economy that expects women to bear the brunt of care and feeding labor in its failures and injustices.

Albeit strongly critiqued as essentializing caregiving labor as intrinsic to women, the work of Carol Gilligan (1982) and collaborative scholars describes "an ethic of care" that complements an understanding of morality as concerned with justice and hints at the existence of a "women's morality". Many food caregiver women I have spoken to through my work have 
indeed described themselves as "born to do this work" and having the need to feed and care for people "in their blood". Furthermore, in her discussion on "moral geography of mothering", Holloway (1998) discusses the responsibility for care that mothers feel and the pressure that is put on them to be "good mothers", even outside of their own families. Feeding, one of the most important assumed labors of mothers (of children and communities alike), certainly qualifies here. This study seeks to explore whether women discern themselves as being responsible for these labors and what role socialization plays in their decision to execute it.

\section{Chapter 3: Methodology}

This research study builds upon 2 years of action research conducted in the Food Justice Lab at West Virginia University: the implementation of the Nourishing Networks Program food access workshop training program. This action research program consisted of 6 food access workshops which demonstrated the gendered and racialized labor within West Virginia food systems (See Section 1.1 for more). This study employs a qualitative methods design and seeks to find answers to questions through verbal communication through discussion with research participants. As Lapan et. al. (2012) indicate, qualitative research, as opposed to quantitative studies, emphasizes the study of phenomena from the perspective of insiders. Quantitative researchers aim to create generalizations and attempt to remain independent of the phenomena they are researching. A qualitative methodology which considers context and subjectivity is best suited for this study as my subjectivity inspires the research and I aim to immerse myself in the perspectives and experiences of food caregiver women in WV.

The decision to collect qualitative data in an effort to seek answers to the overarching research questions can be justified in several ways. First, I already had pre-existing working relationships with some of the research participants. Because of this, an amount of trust and comfort already existed with some informants and qualitative interviews provided the context where deeper conversation could occur resulting in the collection of an optimal quantity and quality of data. Second, storytelling became a very apparent and significant part of each interview. Within each interview session, first-hand accounts from the field or secondhand accounts from clients of the informants were articulated. Quantitative data gathering methods alone would not adequately address the guiding research questions of this study, as the main objective was to gather the perspectives and experiences of individual people. 


\section{Chapter 4: Research Questions, Design, and Methods}

\section{$\underline{4.1 \text { Overview }}$}

My research builds on preliminary data in the form of participant observation through facilitating 6 food access workshops in Wayne, Fayette, Logan, Calhoun, Wetzel, and Wood Counties in West Virginia where women were disproportionately represented in attendance as laborers in the West Virginia food system. During these 6 pilot Nourishing Networks workshops, it was clear that gender is an important variable determining food security in WV counties. Single female-headed households had poverty rates that were significantly larger than the rate of poverty for households overall in each county. In addition, $85 \%$ of workshop participants and $100 \%$ of the county action teams that developed from the workshop to carry food access strategies forward were women. This demonstrated how women are not only disproportionately affected by hunger, but that they disproportionately labor to remedy it. Through these observations as well as my own experiences as a food caregiver in WV, I became interested in answering a series of questions regarding this labor through a feminist lens.

\subsection{Guiding Questions}

- How do West Virginia women working in the food system (food caregivers) understand and describe the relationship between food, care work, and justice?

- How do food caregiver women describe the motives and rationale for their labor?

- How do food caregiver women perceive the role of their identity in shaping their community organizing efforts for food security?

- How do food caregiver women explain and understand the preponderance of women providing caregiving labor in WV food systems?

\subsection{Research Study Design and Methods}

The West Virginia University Institutional Review Board approved the research study protocol and exemption was granted in December 2019. A total of 13 participants took part in the study and engaged in in-depth individual semi-structured interviews following approval. All interviews took place on the phone except for 1 which took place in person. All interviews were recorded on two separate devices upon gaining the interviewees' consent. Interviews were later 
transcribed first-hand on a computer. Throughout the data collection and analyzing process, 3 rounds of manual coding ensued.

This research employs a phenomenological study that utilizes narrative inquiry to answer a series of guiding questions. Merriam \& Tisdell (2016) state that phenomenologists are interested in lived experiences and that this type of focus requires the researcher to immerse themselves in the research and go directly to that subject matter to explore it. "Phenomenology is a study of people's conscious experience of their life-world; that is, their everyday life and social action" (Schram, 2003, Pg. 71). Creswell (2013) posits that the researcher should complete the study and should walk away with the feeling that they understand what those lived experiences may be like for that person or people better.

Selective sampling was utilized in research participant recruitment. A diversity of participants who I had pre-existing relationships with through community food work with the Food Justice Lab were selected. Sampling was done across organizations, sectors of the food system, and across racial identities. I identified women food caregivers in several of the 6 counties where Nourishing Networks workshops took place as well as from outside of this work and preliminary research process, and found it important to explore why and how these women are taking on the role as organizers, feeders, and caregivers in their communities. To follow up with these women and others who are feeding and caring for communities, I administered semi-structured interviews either in person or over the phone with 13 research participants. As Longhurst (2003) describes in regards to the nature of semi-structured interviews, interviews were guided by a list of predetermined questions, and interviews unfolded in a conversational manner in which informants could tell stories, expand on answers, and explore topics not directly asked in questions (Pg. 103).

Through individual interviews, I answered motive and rationale questions that could not be answered without gaining perspectives from the standpoint of food caregiver women who witness food insecurity and capitalist food regime failure and strategize to combat the hunger that results from it. Furthermore, my research documents the stories of these women through personal narratives. With participant consent provided, audio from all interviews was recorded for transcription and analysis. Interview participants all agreed that it was okay to use their names and indicate their job positions in presentation of interview data, however, I have chosen to keep informants anonymous throughout the research process and thesis. 


\subsection{Data Analysis}

This research study utilized deductive coding, as I knew various themes that would arise going into the interview process. For example, because some questions explicitly asked gender questions, I was able to pinpoint what themes were directly related to gender. Similarly, some questions were explicitly around race and whiteness, there were therefore coded accordingly. However, inductive coding also took place, as the semi-structured nature of the interviews allowed for various unexpected codes and themes to emerge. Several participants shared deeply personal and unique individual experiences, and various unexpected themes emerged. Outliers were identified throughout the coding process, although there were few. Initial note taking took place during the interview process. Following the completion of all 13 interviews, interviews were transcribed first-hand by the researcher on a computer and 3 rounds of coding ensued.

Thematic coding in qualitative research consists of a series of processes that enable collected data from interviews to be sorted and categorized which allows for the construction of meaning behind the data (Williams \& Moser, 2019). This provided thematic directionality toward categorizing data through which meaning was negotiated and presented in writing (Williams \& Moser, 2019). As previously stated, the coding process for this study took place in 3 parts. The first round of coding was the initial open coding where distinct concepts and themes were identified during the interviewing process (See Appendix B for a list of these codes). The second round was the axial coding phase, where themes were refined and categorized into overarching categories following a close reading of typed transcriptions. The last phase of the coding process was selective coding, in which the data from the axial coding phase was further refined and placed into more meaningful themes which would support the arguments made in this research study.

\section{Chapter 5: Women as Food Caregivers}

\section{$\underline{5.1 \text { Introduction }}$}

Through both working directly in West Virginia food systems and conducting action research over the last several years, I have seen women disproportionately labor to repair a broken food system. Women are not only growing food, feeding their families, selling it at the grocery stores, serving it in restaurants and schools, and distributing it in food pantries, they are organizing their own communities and organizing for policy change to combat systemic 
problems at the root of hunger and malnutrition. Women have been referred to as "feeding the world" and often work to combat hunger not only within their own families, but for entire communities and beyond. Related to this, care work is typically provided by women both inside and outside of the home across the globe. According to a report from the International Labor Organization, women perform $76.2 \%$ of total hours of unpaid care work worldwide, which equates to more than three times as much as men (ILO, 2018). Through participant observation from preliminary Nourishing Networks efforts as well as direct engagement with food caregiving work in the state, I can confirm that this is also true in the context of West Virginia. During the research process, women were asked why they believe it is women that disproportionately perform caregiving and feeding labors in the state of West Virginia. Among the interviews, participants indicated that they felt they were both socialized into caregiver roles as women and that biologically women are better equipped to perform the labor. Interestingly enough, even women who described the clear socialization of women into the roles also described how women veered toward this labor because of natural instincts and capabilities. In the paragraphs that follow, I explore their responses and perspectives on socialization into food caregiver roles, women as natural nurturers, why men perform this labor less often, and the devaluation of this type of care work.

\subsection{Socialization into Caregiver Roles}

Many participants agreed that societal pressures and expectations of women have led to women performing the majority of food caregiving labor in the state. One white participant involved in university extension education made the statement, "Women have been determined by men as the ones who are supposed to take care of people." Although all women described the value in their work and voluntary choice to do it, most also indicated that society does indeed expect them to hold these community caretaker and food caregiver positions in society. Another white-identifying interviewee who works in education and research said, "Most care work performed by women because of how women are socialized as caregivers, nurturers, and child bearers. We tend to veer towards this work ... There are some intrinsic values in being a woman that leads us to being more observant and wanting to nurture more ... but a lot is the way we are socialized because we have to be this way." Although this participant described certain values as being intrinsic to women, there was an understanding that much of why women participate in 
this type of labor has to do with socialization into the roles. Socialization into these roles was often discussed in connection with love and compassion. We see an example of this provided in the last quote where the same participant described a desire to nurture that exists within women. She stated, "I think, in that way there's also this aspect of a compassionate intuition in a lot of women that we are socialized to have." The use of the word 'intuition' implies an instinctive reaction rather than a conscious reasoning around the act of being compassionate. However, this 'intuition' is described as being socially produced. Some participants' statements were often conflicting, claiming both biologically present yet socially produced qualities surrounding women. A white informant who engages in advocacy and organizing in her work described the work in terms of nurture and love, "If you feed someone to me so they have their needs met. That's like... that's nurturing and loving."

Several participants also described a 'traditional' patriarchal culture particularly strong in West Virginia that places women in feeding and caregiving roles as shaped by societal expectations. One interviewee who identified as white and whose primary role is in agriculture as a producer stated that although she does not agree with it, many people in WV maintain that men are to be more business-minded and should be the breadwinners of the home, whereas women are to be homemakers and care for the family in a more domestic role. She quoted, " $I$ think that there are paradigms, systems, and expectations that have been created throughout history and societies where men are supposed to be the breadwinners and are business minded, right? Where women have been cultivated to be nurturers and caregivers." Another white identifying participant who labors in a food pantry made a similar statement, "I think that traditionally in West Virginia the man worked and the woman stayed home. I think that women from West Virginia feel the need to help each other and to be the caregiver. When the guy goes out and makes some money and the woman is the caregiver, and whether that is for a child, her family, or for her community, I think that's just the way we are raised."

The socialization into being a caregiver begins during childhood for many girls. Being raised in West Virginia and experiencing this type of socialization since childhood was mentioned by a few participants. Another participant who identified as white and is involved in university education and research described how she was raised in contrast to her brothers when it came to learning caregiving behaviors. She quoted, "In my house, I was the one that had to learn how to cook. My older brother didn't. He wasn't held to the same kind of standards ... My 
mother said, 'you need to know these things, because you're going to need to be the that is going to be providing these sort aspects in a home or relationship or in a marriage." A white participant whose role in the food system is in agriculture and policy also connected back to a patriarchal culture still present in the state as well as how food caregiving work is often undervalued and underpaid when she stated, "It's not in my case, but it could be that men are so the primary breadwinners. And so if a woman is working in caregiving or food security, they may be doing it as a volunteer or at a reduced wage of what they could be earning ... They don't have to be the major provider, financially."

\subsection{Women as Natural Nurturers?}

The idea that women carry some sort of natural capacity or innate desire to provide caregiving labor for others is fictitious and only bolsters gender inequality by burdening women with responsibility for this labor and justifying their employment in low paid care work positions (Meyer 2000; Makina 2006). However, when interviewees described why women more often than men are found in these food caregiving positions, they often referred to skills unique and biological to women. All interviewees, at least in some way, described that it is because of certain inborn qualities that they are able to perform this labor - whereas many others, often including men, could not - at least not to the same capacity. Even when women indicated that women are socialized to be nurturers and are often pressured with the task of feeding and caregiving, many still indicated that women are naturally or biologically nurturers, saying things like "it is in my DNA", "women are wired this way", and that "women are inherently more compassionate" or have a "caring intuition". One participant who identified as African American and engages in community development work stated, "Feeding someone is an intimate, nurturing act. And I think that's something that's something that is natural to women. I know there are men that may nurture, too ... but I think being a nurturer or something that's very true with us and feeding and providing food is something that I think is intimate and wrapped in that nurture. So it's easier for us just to do it by nature." At the same time that the work is described as being incredibly difficult and demanding, it is also referred to as being easier for women by the women who do it because it calls for a nurturing nature which women inherently possess. Another white participant who works in one of 2 food banks in the state described how she believes women are naturally motivated to serve and meet needs. She stated, "I think it's part of 
maybe our nature and our wiring. And how we're brought up. I think it's natural and internal to want to see families thrive. I think it's how God made us and it's our wiring. I mean we see a lot of men, too. But in Family Resource Networks we do see a lot of women. We really care about kids; you know? But naturally I think women are called to and motivated by helping and serving. It's how we are wired a little bit. And I think it's a different work that we need to fulfill with men and women. It's a different need that fulfills us." Not only are women described as being naturally 'wired' to complete this work because of their innate desire to help and serve others, but the labor is also described as being particularly fulfilling to women. Scholars have explored how caregiving can be an empowering act for the caregiver, and that helping others and meeting needs can allot power and a sense of ability to the caregiver (Bubeck 1995; Gilligan 1982). Women may be more motivated by this type of power and empowerment, and feelings of selfrespect and worth may be associated with being needed and their ability to help others (Bubeck 1995; Gilligan 1982).

\section{$\underline{5.4 \text { Why Not Men? }}$}

When describing their perspectives on why women tend to be the ones to engage in feeding and care labor, the subject of why men do not was often brought up organically. A few participants described the reasoning for this to be related to the strength of women. One notable quote from an informant who identified as black and is well known in her community and involved in policy, organizing, and education included, "Honestly, I do feel that there are more females in this industry because they are stronger. It's not about sympathy. It is about empathy. And they believe someone who has gone through it." This statement indicates that women are able to empathize with others because they experience certain hardships that men may not. Some women justified these ideas not only by speaking on the strength within women but also by describing how their own husbands would not be equipped to effectively do the work. One white participant who works in university extension education stated, "Women are the strongest number one ... I think that we are more tuned into the people that are of people's needs. As a woman I feel like I can actually do multiple things at once. My husband who I've been married to for 26 years; He has to stay on target with one thing at a time." Describing the skill to handle multiple things at once may be speaking to the complexity and difficulty of food caregiving work. Another biracial informant who works in public health and university education and 
research made a similar statement about her partner, "I think women are doing this work because it's hard work and we're strong. I mean, I love my husband to death, but he could not do this work. And he does hard work - he does physical labor for his long-term job. He deals with death and families screwing each other out of inheritance every day. But for that job, he's able to turn it off. " Here food caregiving work is described as being even harder than jobs that require physical labor. Noting that her husband has the ability to 'turn off' his work after a shift implies that some elements of this interviewee's labor continue to affect her even after the working day ends. She went on to confirm this and explain how she loses sleep knowing that there are unmet needs where she could be offering support. This further supports the claim that food caregiving work is incredibly emotionally demanding on the caregiver.

Discussions around men performing this labor did not imply that men are not capable of food caregiving, but that women were simply better equipped to do it. This sentiment is represented in the statement of one white participant who works in university extension education, "I don't know that men aren't equipped to do it. I just think that we [women] can do more." Also quoted by another white-identifying interviewee who works in charitable food at a food pantry, "I'm not saying that men don't [give of themselves and their time]. It's just like second nature to them where it's first nature to women."

Another reason that less men occupy food caregiver roles may be that feeding and providing care are associated with a feminine identity. Bubeck (1995) describes how care and service are characterized as feminine and that these ideas may be deeply internalized within women. Masculinity is as fragile, if not more, than femininity when it comes to identity. Men are also policed on their masculinity and have more to lose by not conforming, considering their privilege and power in society (Bubeck 1995). Because of this, men reject and suppress 'caring' aspects of themselves at risk of having an identity associated with femininity, and therefore an identity or occupation that is devalued (Bubeck 1995).

Scholars have described the ways in which labor has been socially constructed into categories that either give it value because it creates economic production, or is devalued because it is unassociated with economic production (Degler 1980; Ryan 1979). Care work falls into the devalued category because it is associated with work often performed in the home and labor that is often unpaid. Because women tend to bear the brunt of domestic labor within the home, ideas of 'men's work' (labor men disproportionately perform) and 'women's work' (labor 
women disproportionately perform) are socially divided. Cancian (2000) describes internalized ideas about 'natural' differences between men and women that lead to socially constructed ideas about how they work in her statement, "Caring for others came to be seen as naturally growing from women's maternal instincts, while ruthless competition at work grew from men's natural aggressiveness" (Pg. 139). One white interviewee working in charitable food seemed aware of these social ideas and societal pressures. She compared rejecting care to pride within men in her statement, "And I think that it's another thing is pride. Guys don't want to see you to see that in them".

\subsection{Devaluation of Women and Care Work}

Cultural and social ideas devalue women and thus, by cognitive association, devalue care work which is typically done by women. Simply put, female-dominated jobs involving care are especially devalued because performing care is a quintessentially female/feminine identified activity or labor (Cancian \& Oliker 2000, England \& Folbre 1999, England et al. 2002; England 2005). The myth that women have some sort of natural capacity and innate desire to care and serve reinforces gender inequalities and disproportionately burdens women with the responsibility to provide care - often for little to no wages in return (Abel 1990; Hooyman \& Gonyea 1995). 'Women's work', or jobs associated with femininity are valued less and paid less than 'men's work', which is associated with masculinity. Caregiving labor is defined as 'women's work' in society and therefore is devalued. Occupations characterized as requiring specialized knowledge and skills are typically higher paid, and because caregiving is seen as a natural ability of women that does not require specialized skills (it does, of course), the labor is typically lower paid and thus devalued and depreciated (Cancian 2000). England (1994) supports this argument and poses, "Nurturant work is devalued in markets because of its traditional link with women's work in the home and in labor markets, " (Pg. 182).

Most interviewees across various races indicated that they felt society has expectations that women feed and care for families and communities - though the work is undervalued and underappreciated. Women are expected to perform the same work even when it is not exchanged for wages. When asked about her caregiving and feeding labor, one white-identifying interviewee involved in advocacy and organizing stated. "Women are obviously the ones who hold this shit down, even though we don't get credit for it". This statement indicated a 
depreciation of the work. It suggests that women are not credited for their accomplishments in the food system work as well. Indeed, in West Virginia women tend to be working on the ground delivering food, in kitchens cooking food, and in classrooms teaching nutrition and agricultural education. Men who do occupy roles in food system work often take the place of director and manager positions. Another interesting quote from a biracial-identifying participant engaging in public health and university education and research stated, "I think women put up with a lot of shit all the damn time. And we also know what it means to stand up for something to be done. We do it because it is hard work and we are strong - even though we know people will be condescending to us." Women are expected to do the work, and often embark on this labor knowing the prejudices and maltreatment they may face in doing so. Food caregivers are aware of the devaluation of care work, yet disproportionately perform the labor both inside and outside of the home. Furthermore, they are aware that they are being grossly underpaid as women to perform the labor. When asked why it is that women do most feeding and caregiving work, one white interviewee involved in agriculture and policy laughed and stated, "Good question. They are the only ones who will do it for the shitty pay. I'm sure you've heard that one before [in other interviews]."

This condescension and maltreatment go beyond gender. A participant who identifies as south Asian and Hispanic connected race with the devaluation of care work in her statement, "As a woman of color, some people think the things I care about must not be important - since I care about it ... those issues get devalued because women care about them." When race and gender intersect, women of color have many more struggles with their work being valued. For example, a wage gap has always existed between men and women with women earning significantly less, however, many have found that wage discrimination exists across race and ethnicity with minorities earning significantly less than white laborers in the same positions (Berheide et. Al 1987; Dill et. Al 1987; Remick et. Al. 1987; Ross 1987; Tomaskovic-Devey 1993). Furthermore, the majority of women of color are found in occupations that are already dominated by women, yet are concentrated in the lowest paid positions of the work (Reid 1998). Because women of color are subject to discrimination based not only on their gender but also on their racial identities, they often earn even lower wages than white women (Dill et. Al. 1987). As supported by the quote from the food caregiver regarding her perspectives being devalued and also 
supported by existing research, devaluation is multiplied along lines of not only gender, but race as well.

\section{Chapter 6: Food Caregiver Visions of Food Justice}

\section{$\underline{6.1 \text { Introduction }}$}

In the case of food justice, various academics take their own perspectives but tend to follow along similar lines and include much the same themes when defining it. Academics have done much work to define what "food justice" includes as a concept, but much less literature exists on exactly what it means to be doing the work or what constitutes as "doing food justice". Cadieux and Slocum (2015) analyze food justice literature and conclude that effective food justice organizing seems to include the following elements: "1) acknowledging and confronting historical, collective social trauma and persistent race, gender, and class inequalities; 2) designing exchange mechanisms that build communal reliance and control; 3) creating innovative ways to control, use, share, own, manage and conceive of land, and ecologies in general, that place them outside the speculative market and the rationale of extraction; and 4) pursuing labor relations that guarantee a minimum income and are neither alienating nor dependent on (unpaid) social reproduction by women" (Pg. 13). These qualifications exclude much of the labor that makes these incredibly transformative shifts possible, including the meeting of short term food security and care needs that would sustain the transformative efforts. A much smaller group of people may be able to engage in work at that level and include all of the above elements that constitute effective food justice organizing.

This project which explores the concept of "doing food justice" through preliminary action research findings and work perspectives of 13 women in West Virginia and considers whether the perspectives of those with boots on the ground can inform a reimagining of what constitutes food justice work. Although these labors may not include all of the elements which should be included in what is considered food justice organizing according to Cadieux \& Slocum (2015), they may meet needs that are crucial during the food justice organizing process and have an impact that is not made visible without engaging in the work directly to explore its capacities.

In this study, I look to food caregiver women engaging directly in this community food security work to capture their visions of food justice and the potential of their labors to fall into these transformative descriptions of food justice work. During interviews, I provided each 
participant with a definition of food justice based on current literature. I described that food justice represents transformation of the current food system, including but not limited to eliminating disparities and inequities (Gottlieb and Joshi, 2010). Furthermore, I added that it can be considered the right of communities everywhere to have equal access to the production, processing, distribution, access, and ability to eat good food regardless of race, class, gender, ethnicity, citizenship, ability, religion, or community (IATP 2019). I explored whether expert perspectives and ideas from food caregiver women call for an expansion of what academics currently qualify as being included in food justice work and creating transformative food system change. Five overarching themes emerged during interviews when discussing food justice including: the critical need to contextualize food justice in a racialized landscape, deconstructing race-based trauma by creating spaces for learning and healing, pain and discomfort, smaller steps toward a larger goal, and considering history and a shifting culture.

\subsection{Food Justice in a Racialized Landscape}

Race is a foundational structure of life in the United States and every system (E.g. education, health care, the food system, etc.) was constructed by and for white people (Billings $\&$ Cabbil 2011). Although whiteness may be strikingly obvious to some, it's power can be less explicitly visible to those who benefit from it. Diangelo (2015) describes the power that lies within whiteness, "This systemic and institutional control allows those of us who are white in North America to live in a social environment that protects and insulates us from race-based stress. We have organized society to reproduce and reinforce our racial interests and perspectives. Further, we are centered in all matters deemed normal, universal, benign, neutral and good. Thus, we move through a wholly racialized world with an unracialized identity (e.g. white people can represent all of humanity, people of color can only represent their racial selves)" (Pg. 1).

Billings and Cabbil (2011) explain further, "For most of us, living and working within the confines of our particular racial group constitutes normality. Even as we are ever more a multiracial state, the vast majority of us are like ships passing in the night. We come close to each other, interact in commerce together, but are navigating separate channels. We rarely board the other's vessel. Since to many white people, if not most, racism is invisible, whites participate in its perpetuation because we lack understanding of its history. A critical analysis of 
power and privilege that is needed to interrupt this structural arrangement is absent from our schools and institutions" (Pg. 107).

Incredibly few people of color occupy leadership positions in food system work positions (E.g. alternative food, nonprofits, charitable and state agencies) in WV and the U.S. (Billings \& Cabbil, 2011) which begs the question of whether a diversity of perspectives, experiences, and concerns from persons of color are also being considered in organizing and strategizing. This is one way participants noted that race shaped the food system in WV. Several participants across racial identities noted that the right people are not in the room when planning takes place and indicated that rooms where organizing happens are often filled with white men and women. Because of the overwhelming whiteness in WV food systems, increased leadership of POC and their participation in organizing and strategizing is crucial. It was noted that because POC have intentionally been kept out of these spaces, it is the responsibility of white people in these current roles to do the work to consciously be inclusive and work against regenerating whiteness in WV food systems. Indeed, this whiteness is not inherent to the food system. As Saldanha (2006 as cited in Slocum 2006) states, "While the ideals of healthy food, people and land are not intrinsically white, the objectives, tendencies, strategies, the emphases and absences and the things overlooked in community food make them so... How this food is produced, packaged, promoted and sold - engages with a white middle class consumer base that tends to be interested in personal health and perhaps in environmental integrity. White, wealthier bodies tend to be the ones in Whole Foods, at co-ops (e.g. in Syracuse's Real Food Co-op, the Wedge in Minneapolis), the people attending CFSC conferences, those making certain purchases at the St. Paul Farmers' Market and the leaders of community food nonprofits. Here, whites come together, stick together and then become impenetrable to others despite their desire to be otherwise" (Pg. 7).

When asked about how to work against whiteness and racism in the food system, it was noted by both white participants and participants of color that the simple acknowledgment of those issues was an important first step. Whiteness at times goes unnoticed by white individuals who benefit from it, and in spaces that are overwhelmingly white, acknowledgment of its presence is oftentimes nonexistent. According to participants, notably participants of color, equally as important as acknowledging whiteness and racism is having conversations about it. It was noted that white discomfort and at times pain from people of color will go along with these 
conversations, but that they are imperative in moving toward a more just and equitable food system that serves all people. One participant noted that black and brown hunger is different from white hunger, and stories of being racially discriminated against while accessing assistance resources or for eating certain foods were common in interviews with women of color. Directly experiencing racism influenced how food caregivers envisioned the concept of food justice, with participants of color noting the importance of calling out racism and empowering and supporting people of color.

If food justice work is to be done properly, many food caregivers suggested that it must be acknowledged and discussed that the food system operates within a very racialized landscape. Leadership cannot be solely in the hands of white people in a food system designed overwhelmingly by and for white people. Whiteness is a certain obstacle in WV food systems which will not be overcome unless more people of color occupy leadership roles and are at the tables where organizing and strategizing occurs. Solutioning problems that exist in a food landscape underpinned by white supremacy requires a complete shift in how the food system, food access, leadership, and race are perceived. Billings and Cabbil (2001) call for addressing racism in the food system through new strategies and approaches based on a collective understanding of racism and its manifestations. "Denial, silence, and tolerance in the face of racist policies and practices must be replaced by a sense of urgency to undo racism. White people need to challenge ourselves to feel this sense of urgency and stand in solidarity with people of color as anti-racists. Together we will be able to learn what racism looks like in the food system; we will be able to assess our behaviors and roles in perpetuating personal and structural racism; we will be able to take intentional and accountable action to combat all forms of racism" (Pg. 111).

\subsection{Deconstructing Trauma by Creating Spaces for Learning and Healing}

Experiencing racial oppression directly shifted how nonwhite participants envisioned the work that was necessary for food justice to occur. Specifically, participants of color argued that to create a more just and equitable food system, acknowledgment of the presence of trauma as a result of lived experience through racial discrimination is necessary. Furthermore, healing from these traumas is essential for those who have been forced to live with them throughout their lives. One participant who identified as African American and is involved in community 
development work noted that she had no idea that she was being done unjustly until she was told so by someone else who had easier access to better quality and quantities of healthy food in their white neighborhood. She shared, "So, I told him before you come in the community and tell me that I'm being done wrong, you have to teach me that there is a better way. When you're going to get supermarket, your vegetable area is just three feet wide. But when you go to the other Kroger's on the other side of town their vegetables are nine feet wide ... But I never connected it toward injustices. I just thought this was the way it was. So I've seen that it's very important, especially with marginalized people, that a lot of times you have to even show them that they're being done unjustly. Because if injustice is all that you ever had in your life, that becomes a normalcy for you. When someone externally would say 'Oh, you're apathetic'... No, I'm not apathetic. This is just all I know. I didn't know that I was done injustice. I didn't know that there was a food desert. I didn't know that if we band together we can make a change. So I think it is important to not assume that this information is readily available in communities, because if the community knew this information, it wouldn't have been marginalized."

Discussions about race in the food system with those who have directly experienced racism changed the scope of what should be included in justice work, including widening it to include addressing whiteness and creating a space where open conversations can happen about trauma and emotions can be expressed as an important step moving forward. Years of trauma caused by generations of racism in the U.S. not only shapes the food system but also detrimentally impacts people. This was demonstrated by informants of color who described their experiences rebuilding their identity after internalizing ideas based on race and healing from race based trauma. Racism can be a traumatic experience that can permeate all areas of a person's life. Carter (2007) poses that because of its pervasive nature and because racism has existed for hundreds of years, society can cause people to become physically and emotionally vulnerable. One participant of color who engages directly in communities with her development work indicated that she had to deconstruct internalized ideas to rebuild her entire identity and sense of self after years of racial discrimination and injustice prior to beginning this work. She stated, "I come from a marginalized community ... I had to rebuild my identity for me to even become a healthy mother, to a healthy wife, to a black woman, to a successful woman, to an independent worker to be in my to guiding my own destiny, and to be my own. So I had to kind of restructure all that ... and every day truthfully I go through the process. The internalizing of a lot of 
discrimination and racism that I was taught takes set ... What I focus more on deconstructing is the internal racism and internal discrimination that I was taught to accept. So I'm doing a lot of the deconstructing and making sure I don't think within that mold more than anything." Here justice work while structural, social, and cultural is connected to the more intimate work of combating internalized oppression. As this participant noted, it is a daily practice.

In addition to internalized oppression, others highlighted the role of micro-aggression and aggressive behaviors. Another biracial participant of color stated, "I have experienced racially motivated attacks and one person went to jail." She chose not to go into further detail. Women of color are experiencing acts of racial violence, which undoubtedly leaves them to deal with trauma and mental distress. Importantly, these food caregiver women share the valuable insight that part of combatting a racist food system includes coming face to face with and recovering from the traumas and internalized ideas that have developed in those affected. Addressing these matters is pivotal in ensuring that people and communities are resilient and empowered in their efforts to do food justice work.

\subsection{The Importance of Conversation Around Race}

Creating a space where conversations about whiteness, race, and racism materialize cannot exist without feelings of pain and discomfort for those who have experienced it. When asked about whether it is easy to talk about whiteness and racism in their organizations, many participants across racial identities indicated that they found it very difficult but for different reasons. Carter (2007) states that people of color often experience various types and levels of racism (E.g. individual, institutional, cultural) which can lead to deteriorated physical and mental health. People of color may experience numerous life event stressors and receive little societal support which can exacerbate the problem and lead to disorders such as clinical depression, anxiety disorders, PTSD, or personality disorders (Carter 2007). One African Americanidentifying participant discussed how this racism can become internalized and accepted, shaping the way that problematic relationships develop within food justice work, "And then I think, the people that have been marginalized... if we don't believe internally that we can make a change... We just accept that client mentality and we internalize this racism and we internalize discrimination and then actually play the part to make it easy for people to constantly just come in and just play the Superhero and walk away feeling good." When asked how her experiences 
and ethics connect with her choice to do the work she stated, "I'm coming from the hurt people and I understand what it feels like to be hurt and the difference between living that way and being in the process of knowing that there's liberation and being in a place to create liberation."

White interviewees noted that they often feel uncomfortable discussing the topics, and therefore the conversations are prevented from occurring. When asked if it was difficult to talk about racism in her organization one white participant working in a food pantry stated, "It's difficult to bring up, even though it's the right thing to do ... it's difficult to make sure you're being politically correct." These conversations are actively avoided because of the discomfort that can come with having them and being called out on one's own racism.

Diangelo (2018) describes this white discomfort in talking about race and acknowledging privilege as "white fragility". She describes this concept, "Socialized into a deeply internalized sense of superiority and entitlement that we are either not consciously aware of or can never admit to ourselves, we become highly fragile in conversations about race. We experience a challenge to our racial worldview as a challenge to our very identities as good, moral people. It also challenges our sense of rightful place in the hierarchy. Thus, we perceive any attempt to connect us to the system of racism as a very unsettling and unfair moral offense. The smallest amount of racial stress is intolerable - the mere suggestion that being white has meaning often triggers a range of defensive responses. These included emotions such as anger, fear, and guilt and behaviors such as argumentation, silence, and withdrawal from the stress-inducing situation. These responses work to reinstate white equilibrium as they repel the challenge, return our racial comfort, and maintain our dominance within the racial hierarchy. I conceptualize this process as white fragility" (Diangelo 2018). Nonetheless, participants of various races indicated that these difficult conversations are central to progressive change, regardless of whether they were occurring within their organizations or not.

One white research participant who engages in university education and research stated in our discussion, "It is uncomfortable for a lot of white people to talk about because it involves acknowledging privilege. Some people think that racism is over. Every white person is inherently racist because we are socialized to believe that the color of our skin makes you superior or privileged. I'm privileged to know these sorts of things, even if they are so very painful sometimes." Several participants discussed the reality of white privilege, and a few noted that oftentimes white people do not realize they have it because of the whiteness of the society they 
live in. When discussing whiteness, one white participant who works in a food bank said, "There are very few people of color, very little diversity, but I think maybe my own whiteness is that because I've lived in West Virginia and I'm from West Virginia. I'm just used to that being the makeup of the room, you know? I mean there isn't a lot of diversity. I don't expect that or look for it just because I've grown up and that is the case. It's not an intentional thing, but it just doesn't occur to me. I will say that my own whiteness is just being used to everything. I mean not having diversity and not thinking about it because of that ... It hasn't come up a lot. So it seems to me that to me that we're not addressing it. It's easy to think, 'Well if it's not coming up then it must not be a problem. '” Here we see an example of how easy it might be to avoid conversations about race in spaces that are predominantly white. Because the conversations are difficult and because sometimes few people of color are present, the conversations are written off as unimportant or unnecessary to avoid white discomfort and acknowledging issues of racism and whiteness. A biracial participant of color offered her own perspective working at a university in the state, "Yes, it is difficult to talk about race in my work ... I've gotten in trouble for talking about race and sexual assault in the food system. I was told 'we don't talk about racism here,." This provides an example of how race is intentionally avoided, likely to prevent discomfort for white people or those who are benefiting from the lack of acknowledgment and conversations around race issues. Before they can even begin, productive and informative conversations about racism that may provide a learning opportunity are prevented from occurring.

\subsection{De-politicization of Food Caregiving Work}

Within interviews, participants were asked whether they perceive their work to have short, medium, or long-term goals or a combination of the three. Many described their work to have a combination but described how although their shorter-term work met a more immediate need, it was all part of a bigger picture and worked toward a broader food system change. This question aided in understanding the capacities of these labors to have a longer-term food system change. Shorter-term strategies were re-valued in these conversations.

Although some participants were involved in education, organizing, and policy work which may be categorized as transformative labors, many were involved in work with shorter term goals that address immediate needs. Those involved in charitable, agricultural, and some types of educational labor described how they believed their work to have more short-term 
outcomes which were steps in the long process of achieving a long-term goal with a broader outcome. For example, teaching a cooking class can create a generational shift in how and what a person eats and then teaches their children to eat. Providing families with charitable food such as weekend backpacks of food for children and monthly food boxes sustains families and allows children to get an education and concentrate on their schoolwork. These are the labors which are often criticized for lacking the potential to create a longer-term change. For example, charitable and emergency food has been described as a 'band aid' and solely short-term response to hunger that does not address the root causes of food insecurity (Poppendiek 1998). Likewise, alternative food systems have been criticized as neoliberal in approach because the potential for social change is placed in the hands of consumers, claiming that their market behavior can be a means of significant system change and granting them personal responsibility for transformation (Alkon 2013). Furthermore, community food security and food justice movements are often critical of the neoliberal corporate food regime and seek alternatives, yet reproduce neoliberal strategies themselves (Alkon, 2013; Guthman 2008; Brown \& Getz 2008).

However, it was expressed that if people are not sustained and cared for in the present, a future broader outcome is not possible. One participant who labors in charitable food made the point, "You can't function if you're hungry ... Why not feed people so that they're not hungry and then they can flourish in life and be a productive citizen?" Another informant engaging in policy and education went on to state in her interview, "Because how can you be present around other people? Whether this is a child in preschool or high school... As you get older, that hunger level gets extreme. A preschooler will just whine. A child in elementary school needs more concentration." Hunger can affect people's ability to care for themselves, find work, or receive an education. For these reasons, all participants indicated that their labor was indeed doing food justice work, even if the outcomes of their labors work to meet a more immediate need based on an individual level. These smaller labors are necessary to sustain communities and are historically crucial to preserving movements throughout Appalachia's history. Lest we forget the packs of food given to WV miners on strike and bags of food prepared for children during the $2018 \mathrm{WV}$ teacher strike. These labors are what paves the road to make a longer-term outcome possible. 


\subsection{Patriarchal Culture and Extractive Ruins}

West Virginia and Appalachia in its entirety are spaces where long histories of extractive industry and outside economic activity have taken place and left current populations to deal with present realities of economic disparities, pollution, and cultures of hopelessness. At several points in data collection, a few interview participants indicated an awareness of these histories and systems of oppression and called for their consideration in the work. When discussing food sovereignty and growing one's own food, it was indicated several times that West Virginians have little to no access to these activities because of polluted land and water. Furthermore, it was pointed out that there are few economic opportunities in the state due to both a lack of jobs and very low wages. A reliance on charitable and government assistance was described as "generational" and its cyclical nature was discussed in several conversations with food caregivers.

It should be noted that legacies of these histories also play out more prominently in lower income and communities of color where hunger may also be more prevalent or food resources are more scarce. Racial and socioeconomic disparities exist in exposure to pollution. Much research has been conducted that confirms that lower income communities are communities of color are disproportionately affected by air, water, and land pollution (Mohai et. al. 2009; Gray et. al 2013; Jones et. al 2014). If food caregiver visions of food justice include addressing environmental justice concerns, they need to be synergized with a recognition of environmental racism and efforts to work against its violence.

Considering the history of a region is fundamental in food justice work because a onesize-fits all solution cannot be successful in all places. If long term change is to take place, all systems of oppression need paid attention to and histories of race, gender, and class discrimination cannot be ignored. The accounts shared in interviews support claims that suggest how these histories play out in present-day society in various ways. Food justice then, may include completely de-colonizing the way in which the food system operates and working against historical legacies of disenfranchisement, violence, and environment degradation.

Several participants also indicated that a 'traditional' patriarchal culture exists in the state of West Virginia that discredits and devalues women. Participants across racial identities noted that they have difficulty earning respect, being taken seriously, not coming off too 'aggressive' in their leadership capacities, and getting communities to participate in their programs because of 
their gender and/or race. It was noted that parts of the state are "behind in the times" and "still have old south thinking" which marginalizes women due to their gender or gender and race. A societal shift in these patriarchal ways of thinking and operating are necessary if women are to be valued, and by cognitive association, the care and community food work that they disproportionately execute.

\section{Chapter 7: Care Work and Food}

\subsection{Introduction}

During each interview, I provided a definition of care work consistent with the literature present in my literature review. Like Folbre (2003), I described care work as work that typically involves connecting people to one another, trying to aid people in meeting their needs, teaching, and caring for the children, elderly, and those that are ill. I described that care work is about completing tasks whilst providing both love and labor and the affective relations that take place through this (Abel \& Nelson 1990). After being provided this definition, research participants were asked whether they consider their work to be caregiving labor and why. Though all agreed that their work could be considered executing a type of care labor, the justifications for this claim varied widely.

Four overarching findings emerged throughout interviews and were apparent in many conversations during the data collection process. These findings included: differences in how care is provided and perceived, empowerment and power, listening and conversation (emotional labor in the work), personal sacrifice, and genuine concern and care for people. These emergent themes illustrate that care and food work may have various connections which are dependent on the food caregiver's experience and perception. Perhaps one of the most comprehensive examples of how feeding labor relates to care when asked how she provides care, one African American-identifying participant laboring in community development work claimed, "This is caring labor because it is helping the individual trying to help themselves. It is care work because it is to help someone else and not myself ... I provide emotional care, financial care, care in the form of nurture, care in the form offood - this is culturally important, and care through knowledge." 


\section{$\underline{7.2 \text { Community and Individual Empowerment }}$}

Powerlessness is an attitude that can result from influence of negative past experiences, ongoing behavior, and continued patterns of thinking that are both embedded and reproduced by inequitable power relations and experiences (Rappaport 1984). As discussed previously, powerlessness and hopelessness are cultivated in spaces with little economic opportunity and where histories of extraction have left communities to wrestle with the polluted landscapes and broken bodies that are left behind. Because of this several participants, often involved in education or community organizing and development, indicated that they note a lack of empowerment in WV communities and lack of buy-in to programs that start up in these regions. One white-identifying participant employed in university extension education claimed, " $W e^{\prime} v e$ enabled people to be helpless... we have taken their power away somehow. People feel powerless. And I'm noticing that trend in my county really bad lately. Empowerment is something that's missing from the equation, and I don't know how it got taken away. I mean we've got the odds stacked against us because we've had so many job losses that way. So, it is just a depressed sad state that we've become. I'm not even sure how we got there. I really cannot figure that out other than we took people's power away as if they cannot take care of themselves. And I know people can take care of themselves. We just got to give them back their power."

One participant stated that she finds herself often acting as the cheerleader, best friend, and sister within the communities that she works, cheering people on and advocating for their own leadership. A few interviewees, notably those involved in community organizing and development, noted that they are motivated in their work by the moments of success when clients are empowered to stand up for themselves or build the confidence to advocate for themselves. Carr (2003) claims that empowerment is an inherently interpersonal process in which individuals can collectively create and implement strategies to gain access to both power and knowledge. "As such, empowerment is praxis, a cyclical process of collective dialogue and social action that is meant to effect positive change. Therefore, empowering practice necessitates a modality that can successfully accommodate this dynamic, cyclical process" (Carr 2003).

Those who experience racial discrimination and face food access barriers exacerbated by white supremacy may benefit from empowerment under the leadership of others who possess an internal understanding. In talking about race and empowerment within the work, one African American informant working in community development stated, "Being part of a community 
[motivates me in this work]. I think that a lot of us being part of a marginalized community ... many of us internalize what it said about us and therefore it has empowered us to do better. And I know we can do better from an internal perspective, not only from a perspective of someone needed to help us but us learning how to help ourselves. So, my understanding that and understand that we have to change the rhetoric that we believe within ourselves and the rhetoric that is taught to the people that want to help us - so they can feel more empowered." She goes on at a later point, "I believe that everyone is here and we can become self-sufficient. We need each other and I believe in a village. But I also believe that when we do care, to care in a way that we are trying to create self-sufficiency. So if I teach you how to care, then you can teach someone else how to care. It can be more of a ricocheted effect of self-empowerment - and also shared empowerment - instead of individuals that have to be the one in power."

\section{3 "The Kitchen is a Very Powerful Place..."}

Sceats and Cunningham (1996) describe how the operation of power relations can be witnessed in all activities associated with food and eating - encompassing cooks, carers and consumers. Community food work itself was referenced as being powerful various times during interviews, but the food caregivers themselves were often spoken of in terms of the power that they hold because of their roles in the food system. Indeed, women contribute very heavily to the processing, preparing, producing, and distribution of food across the globe. Counihan (1999) states, "The predominant role of women in feeding is a cultural universal, major component of female identity, and an important source of female connection to and influence over others. Hence, because there are other components of female identity and other sources of their authority, the power of women has often derived from the power of food" (Pg. 46).

One interviewee who identified as black and in involved in organizing and policy work offered, "The kitchen is a very powerful place. You have a lot of power when you make someone a meal. There is something innate about women and nourishment and food: it's natural or like intuition." A white informant who works in agriculture similarly noted, "When women are empowered and educated and still have those nurturing tendencies, really powerful things start happening”. Although the work is undervalued and women engaging in these labors are often discredited, it is described here in a totally divergent way. Here we see how connecting food and people is an action that holds power. Although it can be argued that within these statements, 
women are reifying that women 'belong in the kitchen', they seem to be reclaiming power within the work and working to revalue it as labor.

\subsection{Listening and Conversation: Emotional Labor in the Work}

Accounted for in nearly all interviews was the demanding emotional aspects of the labor that often goes unnoticed. A participant involved in university extension education stated that in her community events, there are days in which they can't get to the educational lesson until everyone gets what they are experiencing off of their chest and talk through their emotions. Another involved in community organizing stated that she feels like a social worker in her job. While discussing difficulties of the work, one white participant who sees clients daily in the food pantry who works in stated, "They don't think the work is stressful either. The emotional part of it they don't get. Seriously seeing those people and hearing those stories ... you know just... I wish that a lot of people would just listen because most of them are ladies. Look at that lady, saying 'my husband died and I don't have a choice'." Commonly expressed by food caregiver women was listening, making sure people felt heard, making sure everyone felt comfortable, putting herself in someone else's shoes, and actively working to not pass judgement.

Not only do food caregiver women seem to perform emotional labor through managing the feelings and emotions of others in their work, but they carry the burden of how emotionally and mentally taxing the labor is for their own mental health. Stories of experiencing mental breakdowns and crying in her car came from one particular participant who identified as white and is working for university extension education indicated in her interview, "Some weeks there is a lot to care about. This is one of those weeks." Another white-identifying participant shared that she actively disengages and disconnects herself from the emotional aspects of her work in order to persevere through it. In referencing her work at a food bank, she quoted, "I detach myself emotionally at work because it is so emotionally exhausting, and I get emotionally exhausted easily." She went on to describe how because of this, she has to adjust her motivations for the work. Rather than be motivated by recognizing hunger and need, she focuses on completing tasks and moving food from point A to point B. Even though many interviewees engage in physically demanding labors within their occupations (E.g. farming, lifting boxes of food, loading trucks, travelling), the work also comes with its own emotional demands that boost the difficulty of the work. 


\section{$\underline{7.5 \text { Personal Sacrifice }}$}

Another element that was made clear throughout the research process was that of the unseen personal sacrifice among food caregiver women. Research participants described labors they do that are outside of their purview or what is required of them within their specific work duties. When asked why it is that women do this food care giving labor, one participant stated that it is because they will go above and beyond to get the job done. Another participant discussed personal sacrifice in her work with university education and research in her quote, "We do it [difficult food caregiving work] because it is hard work and we are strong ... we know people will be condescending to us."

One interviewee stated that women occupy these roles because women are taught to give of themselves and of their time. Another told many stories of her going out of her way to drive clients' places, listen to their stories, visit them, and attend events they asked her to. A participant involved in agricultural work indicated that her work extends into her personal life, and she often finds herself responding to Facebook messages and is in contact with people regarding work matters even at home after her shift has ended. More statements regarding selfsacrifice included not being able to sleep at night if there was work left uncompleted and families of food caregivers urging them to take a break or pay more attention to their own needs. When asked what work she did in the state, one participant employed in public health and at a university as an educator and researcher asked, "All the work that I do or the work that I get paid to $d o$ ? " It became clear through the interviews that this work extends beyond the typical working day hours and that it requires the food caregiver to make personal sacrifices to complete the work in the most meaningful and complete way possible.

\subsection{Genuine Concern and Care for People}

Part of several interviews and discussions included how the interview participant genuinely cared not only about issues of food security, but about people and how they felt equipped to do the labor based either on this interest or personal skills and experience. Food caregivers perform this labor despite knowing that the work will be devalued and that it is often done for low wages or through unpaid volunteer labor. Personal experience with poverty, hunger, homelessness, trauma, crisis, lack of healthcare, sexism, and racism were just some of the factors 
that were listed when asked what brought women to this work which they claimed to care deeply about. One participant working in communities as an extension educator claimed, "You have to care for people in this work and people know when you don't actually care." This statement suggests that elements of care are intrinsic and crucial in the work.

No participants indicated that they became involved or were currently involved in the work for the money or title that came with the position. In fact, a few noted that the pay is relatively low for the work they do, but that they continue it because they genuinely care about people and want to help the communities that they work in. A few participants who engage in education, charity, and organizing work in the food system stated that they would still be involved in the work even without the salary or current title. One interview comment from a biracial public health and university employee included, "You have to give a shit about your community. Not everyone does. Giving a shit has led me to this work - that and not just accepting things how they are. That's where the power is. You're giving a shit, but you're choosing it. You really only have so many $f^{*}$ cks to give." Another white participant laboring in a food bank made the statement, "The big hearts in the community and desire to be like them a reason to get up and continue the work each day. " She went on to say later in the interview, "When I sit back and reflect on [my organization] and my role as part of the team, it's just reassuring to know that at the end of the day - no matter what problem arose - somebody got fed... And that makes it worth it. And we put a lot of care into our work because it has a great purpose and is about fulfilling somebody's basic needs. " It became clear that several participants were in their current roles because of genuine interest or concern regarding the issues, people, and communities involved in the work. Genuine care and concern for humans appears to be one of the factors that lead food caregivers to categorize their labors as related to care work.

\section{Chapter 8: Discussion}

\section{$\underline{8.1 \text { Nature vs Nurture }}$}

Most interviewees discussed being socialized into food caregiver roles, but perhaps more surprisingly, all referred at least once to the biological or natural traits of women that better equip them for the work. Although there is much evidence to support that women disproportionately engage in care work and it is generally accepted that women provide more emotional labor as well, there is very little evidence to suggest that women are biologically or 
physiology better equipped to do so. Furthermore, there is no evidence that supports that men are unable or even less capable to perform this labor. This supports the socialization of women into these roles through societal expectations and demands. Women are taught to exhibit caring tendencies, often as early as children as they are encouraged to play with baby dolls, kitchen sets, and more - toys often not found in the aisle or section for boys. This is only a small part of much evidence that supports the role of not nature, but nurture (socialization) that places women into these caring positions. The pressures put on women to provide care for others do not end after childhood. Women carers are created, shaped, and maintained daily through social relationships, processes, and structures (Butler 1988; Duffy 2011).

Although biological or natural traits were described as being present within women, informants did not describe these traits in a way that would necessarily come across as devaluing them or food caregiving labor. These traits, including the inclination food caregivers to go above and beyond, give of themselves and their time, and genuinely care for others were described as powerful and providing them with an advantage in the work. However, this supports and continues the narrative that women are naturally inclined to choose this work and are better equipped to perform the labor, which is all part of a larger narrative that devalues women and the work that they disproportionately perform. By saying these traits are naturally present in women, the statements build upon social ideas that devalue women and the labor they perform by creating an illusion that these specialized skills occur naturally in women without having to learn them. In other words, by making it seem as though these skills are inherently within women, it invisibilizes the training, education, and learning required to perform this difficult and specialized labor. When these skills are viewed as naturally present, the labor that utilizes them

becomes devalued. This contributes to the work being invisibilized, devalued, depoliticized, and underpaid.

\subsection{An Ethic of (Food) Caregiving}

Duffy (2011) describes how feminist psychologists pose that those involved in care work may learn a fundamentally different way of thinking about the world that includes relationships and emotional response. Furthermore, she notes how feminist philosophers have at times suggested moving away from more individualistic notions of justice to instead consider a shared collective responsibility of care for one another as part of a broader ethic of care (Duffy 2011). 
Similar narratives showed up in various interviews, where participants called for teaching others to care so that they too can go on to teach caring and noted a need for bringing the sense of community back. Building upon this through similar narratives, feminist economists have used language around concepts of care that includes experiences of love and obligation into an economic theory that has excluded such concepts in the past (Duffy 2011).

Love and obligation are interesting to consider in considering an ethic of care. One participant of color engaging in public health and education indicated not being able to sleep at night knowing that there was more she could have done or that there was still an unmet need she could work to address. The same participant discussed at a different point in the interview that it was important to care about the community and other people in the work, and that you have to make a choice to actively do so in the work. At other points in various interviews, food caregiving was described as a labor of love and work that can only be done successfully by someone who genuinely cares about people. This ethic of care in which food caregivers approach their work fulfils not only food needs, but also emotional support and care needs that arise in the failures of a capitalist food regime that ignores demand for and value of care work as performed predominantly by women.

\section{$\underline{8.3 \text { Re-envisioning Food Justice }}$}

Visions of food justice varied vastly, and both personal and work experiences of food caregivers directly influenced their vision of food justice. For example, those who experienced race-based trauma noted the importance of deconstructing these traumas. Those who witnessed a lack of women in leadership roles noted the importance of women-led community food work and organizations. Informants who witnessed hunger first-hand in charities described addressing immediate need as food justice. All informants identified a connection between the work that they do and care and qualified their work as constituting doing food justice work. Food caregiver visions of food justice include care, albeit in differing forms. This care included emotional support, empowerment, leadership development, hearing stories, deconstructing trauma, and much more.

Food caregiver visions of food justice included labors that are not readily made visible when one imagines not only what a food caregiver might do in their work, but also what might be included in a definition of food justice. Perspectives from food caregivers offer a response to 
literature that critiques the capacity of much community food work to constitute doing food justice work (Cadieux \& Slocum 2015; Alkon 2013; Mares \& Alkon 2011; Sbicca \& Myers 2016; Poppendeick 1998; Guthman 2008; Brown \& Getz 2008), specifically scholarship that discusses the discounting of labors that meet a more immediate need rather that a longer-term one (Alkon, 2013; Guthman 2008; Brown \& Getz 2008; Poppendieck 1998).

All the labors that food caregivers are providing work to make up some fraction of a larger movement that is the food justice movement. These labors create change on all levels, from meeting immediate food needs in a food pantry, to teaching education to children, to lobbying for food policy change at the state capitol. Without the meeting of immediate needs, future efforts toward food justice are not made possible. Often, food caregiver visions of food justice include these labors in their definitions of doing the work. Through my conversations with food caregivers, I maintain that there is space for expanding theory regarding what labors constitute food justice work as transformative in nature. Including the labor that lay the groundwork for allowing food justice to take place works to revalue care work and make visible their importance.

\section{$\underline{8.4 \text { Identity and Food Caregiving }}$}

Gender disparities in who performs food caregiving work as well as societal expectations regarding the labor were noted by all participants. However, participants of color noted how race intersects with their gender and how this also influences their experiences. White participants described having difficulty being taken seriously and earning respect based on their gender identities. Participants of color described both their gender and race identities as factors that affect their work. Having to rebuild identity because of internalized ideas about their race, being told not to talk about race, and experiencing racism were noted among informants of color when describing their lived experiences as food caregivers. Women of color have historically been expected and sometimes forced to care for families and communities outside of their own, namely white families (James 1993; Collins 2000; Pratt 2012). Not only has this historically been the case, but even in present times these disparities exist. Several scholars have noted that white middle and upper-class women have made strides in the labor force, but this has sometimes involved transferring their care work labors to others, often low-income women, immigrant women, or women of color (Hondagneu-Sotelo 2000; Milkman 1998; Nakano Glenn 
1992; Romero 1992; Tronto 2002). It should be noted that this study was limited in racial makeup of participants, with 9 participants identifying as white, 2 as black, 1 as African American, and 1 as biracial of Hispanic and south Asian descent (See Appendix C). The experiences of women of color cannot be homogenized, as they varied vastly in each interview.

Within the paid care workforce, these racial and class divisions persist and are connected and intersecting with the gendered associations of the work (Duffy 2011). Gender cannot be considered in isolation, as it risks universalizing experiences among women and furthering whiteness by homogenizing in this way (hooks 1984). When women do hole power in this work, white women disproportionately hold supervisory or leadership positions within care work or the reproductive workforce. Immigrant women and women of color tend to be behind the scenes performing the 'back room' chores that are often unseen, and they often do this with little to no supervisory capacity (Duffy 2011). White informants who noted racism and whiteness in the food system often agreed that more leadership from women of color could be beneficial in improving their organizations efforts. One white participant involved in community organizing noted a personal moment of learning, "Total transparency: I didn't realize how much race shaped society until my executive director was a black woman."

An analysis that incorporates class or socio-economic status would provide an even richer perspective on the experience of food caregiver women in WV. Duffy (2011) reminds us that racial-ethnic and immigrant women are highly overrepresented among certain occupational groups within the care sector, including health care, child care, and food service workers (Pg. 137), and that explaining these phenomena cannot be done with not only an examination of gender and race, but also class and how these intersect with one another. The impact of each of these identity factors and how they interact will influence the experience and perspective of the food caregiver at an individual and personal level.

\section{$\underline{8.5 \text { Revaluing Food Caregiving }}$}

The concept of reproductive labor was first introduced by Karl Marx and Friedrich Engels when they described this labor as crucial for maintaining and reproducing a viable workforce (Marx \& Engels 1861). The two noted that workers would not be productive laborers without being fed and cared for. Furthermore, reproductive labor including providing new workers through human sexual reproduction is necessary for the functioning of a market 
economy. Duffy (2011) describes how these labors seem removed from a market economy at first but are actually intimately connected to it as reproductive labor allows for a market economy to exist and function in the first place. This argument can also be made in describing why food caregiving labors allow for transformative food system change to take place by sustaining people and communities in the first place. Immediate food needs will still need to be met as long-term change happens, and food caregivers who are working on policy and education will need to be fed and cared for throughout the process. By illustrating how these labors lay fertile grounds for change, food caregiving labor becomes re-valued and ideally, so are the food caregivers that perform it.

\section{Chapter 9: Conclusion}

This study has explored the perspectives of 13 food caregiver women in West Virginia through examining gendered and racialized dynamics of their diverse work, their visions of food justice, connections between feeding and care, and their experiences engaging in boots on the ground food system work. Informants have provided valuable insight and shared incredibly interesting experiences that help to create a clearer picture of what it is like for some women engaging in feeding and caregiving labor in the state. The data they provided through qualitative interviews as well as my personal experiences as a food caregiver woman have allowed me to ponder and analyze the above topics as both a partial insider and a researcher gaining experiences from an outside perspective.

Participants had a diversity of responses when it came to describing why it is that women disproportionately provide food caregiving labor. Socialization into food caregiver roles was mentioned in terms of pressures from a patriarchal "traditional" culture in WV and being socialized into these roles as children. However, being naturally inclined to perform this labor based upon biological traits or skills naturally present in women was also discussed, including intrinsically being more nurturing and having caregiver qualities within their DNA or 'wiring'. Although these narratives view food caregiving as powerful, they are likely doing little to dismantle the devaluation of the work. Suggesting that women are naturally equipped to perform the labor implies that the skills it takes to do it are innate and require no specialized training or education to perform successfully. 
When asked why women are doing this work, responses included narratives around women being best equipped because of their strength and capabilities and in terms of being able to complete this tasking labor in a way that is more difficult for men because it requires hard work intersecting with care. Informants laboring across food system sectors described the incredibly demanding emotional labor that they put into their work, sharing that they often feel like social workers and feel emotionally drained and exhausted from providing this type of support. Several women responded that women perform this labor for two reasons: because the work is hard, and because women are strong. References to how women go above and beyond in their work and encounter a lot of personal sacrifice were present in many interviews across food system sector and racial identity.

Interrogated in interviews was the relationship between community food/food system work and care. All 13 participants noted a relationship between the work that they do and caregiving - although the means by which they made these connections differed. Providing care was described in various ways including encouraging empowerment of both individuals and communities, offering emotional support, and experiencing personal sacrifice to make sure the work gets done. Caring for others so that they can be sustained, learn to care for themselves, and also learn to care for others in return were all noted. Care was described as necessary to create stronger communities and networks in the face of food insecurity. The work was seemingly very personal to the food caregiver women that I was privileged to speak with.

Aspects of a moral economy and ethic of care were present, as many participants described being expected to do the work within their families and by society at large. In addition to being expected to do the work, many described not being able to sleep at night until the work was done or until all needs were met. Goodness, fairness, and justice certainly seem to underpin the work that food caregiver women do, although the ways in which they articulated this of course had some variation. Several women indicated the importance of genuinely caring about people in this work, as well as the desire to want to help individuals and communities even without receiving a title or paycheck for doing it. Genuine care for others was a trait described as necessary to be successful in food caregiving work. Given that the work is undervalued and most often underpaid, this indeed seems critically important for those who engage in the work as a career. 
All 13 informants noted whiteness and racism within the food systems in which they work. However, when discussing solutioning for these problems, the conversation seemed a bit more difficult to work through, especially for white participants. In moving forward, it was noted by participants across racial identities that it is crucial to be more explicit in facilitating conversations about racism and whiteness. Although it was noted that these conversations may be difficult (painful for some, and uncomfortable for others based upon identity and experiences), they are incredibly important to have moving forward. These conversations were described as important for healing and learning. Because race-based trauma can occur in people of color based on their personal experiences, healing and deconstructing of internalized ideas about oneself may be necessary. Because of the prominent whiteness in West Virginia food systems and the ability for it to go unnoticed in spaces that are disproportionately white, learning about its power and ability to perpetuate violence and exclusion is important.

What food justice looks like varied based upon the experiences of each food caregiver woman. Food caregiver women, especially those of color, recognize that the West Virginia food system is a gendered, patriarchal, and racialized landscape. Visions of food justice include acknowledging and strategizing around these facts within their organizations and leadership. Moving forward in a more just and equitable manner includes the incorporation of women leaders in the work, particularly women of color - especially given the noted whiteness of community food work in the state. More people need brought into conversation and strategizing, namely those most affected by food insecurity and people of color, who many agreed are largely underrepresented in the work. Food justice, to food caregivers, means providing a space for healing from race-based trauma, deconstructing internalized ideas, and having difficult conversations that allow for more about food system inequalities.

All 13 research participants qualified their work as "doing food justice", although some scholars may critique this based on the short-term outcomes that come of it. Food caregiver women recognize that shorter term outcomes are all part of a long game that leads to longer-term outcomes and broader food system change. Without being fed and cared for today and tomorrow, no one will be sustained long enough to continue the work and fight for more structural change over time. Food justice is a long game. These labors were described as powerful and many informants posited that it takes a lot of strength to be able to perform this type of labor. If a more comprehensive definition of food justice is to materialize, it may need additions that incorporate 
care. For example, if food justice is described as transformation of the current food system, including but not limited to eliminating disparities and inequities (Gottlieb and Joshi, 2010), I might add "... and incorporates all of the caregiving and meeting of immediate needs that sustain efforts and create space for transformation to occur." This addition may help to repoliticize this labor, and ultimately aid in its re-valuation. Both historically and in the present, women organize communities through empowerment, care, and meeting food needs.

This research study contributes to literature on food justice and community food work/organizing, care work, as well as gendered and racialized experiences of women engaging in food system work. It has critiqued the critiques of what constitutes doing food justice work and ideally, left readers to consider what a more inclusive or expanded definition of food justice may include. Highlighted by informants across racial identities and sectors of the food system were the failures of current community food work organizations to organize around race and work to eliminate whiteness - even in terms of simply starting these types of critical conversations internally in their workplaces to plant a seed.

Participants in this study have helped to expand literature on food and care work by depicting it as powerful and valuable. Their perspectives on their work have proven the value it holds and described its demanding nature. Discussions not often considered in existing literature evolved, including the need to deconstruct race-based trauma within food work and food insecure communities and the importance of community empowerment and emotional labor within food caregiving work. This study and the contributions of informants have laid fertile ground for more research studies to expand through similar explorations on topics of food caregiving labor, intersections of gender and race, and the revaluation and politicization of the work.

\section{$\underline{8.1 \text { Resituating Myself }}$}

Entering into this study, I anticipated to hear about all the ways in which women doing community food work in West Virginia experience gender discrimination. I anticipated this because as a woman engaging in this work, it is my own lived experience. I also expected to hear the motives and rationale behind doing the work primarily in terms of socialization into the roles. However, all interviewees also described biological factors that they believe make themselves and other women suited for the work. Although these narratives essentialize the 'nurturing' and 
'caring' nature of women, informants were clearly attempting to revalue the work by framing it in terms of being specialized, valuable skills that equip them with a unique kind of power and ability. However, I also realize how these narratives may be empowering at the same time that they support broader dialogue and social ideas that devalue women and work they disproportionately do by implying that women are naturally more inclined or equipped to perform it.

I suspected that the experiences of white women and women of color would be different based along lines of race and intersections of race and gender. However, I was at times surprised at how much participants were willing to share with me including personal stories of violence, fleeing countries, and being treated like lesser than humans. Racism touches every part of our food system, and food caregivers of color face unique layers of gender and race discrimination in their work yet still labor to help WV communities thrive. The role of race-based trauma and importance of power and employment were uncovered to be by participants of color, and I am very grateful for this knowledge gained through their willingness to share. I proceed forward in my own food caregiver efforts with a belief that I have a responsibility to use my privilege to dismantle whiteness and white supremacy in the food system.

As stated previously, I am humbled at how much participants were willing to share with me and the trust that they showed. Many tears were shed throughout this research process and much learning took place on my part. I am grateful for the kind words of motivation and appreciation that came from time to time at the end of interviews. I am pleased that a result of this study was the strengthening of my relationships with several participants and the blossoming of friendships emerging.

I am reflective of the moments of adversity I have and do experience as a young white woman engaged in community food work. I face discrimination based on my gender and sometimes age, and I am not alone in this. I am reflective on my race and the privileges that it provides me simply by existing within the skin I am in. I wonder how my labors would be different if my race, ability, religion, or nationality were different. My privilege is that I wonder, yet do not experience these things. This wondering shapes how I will move forward in my work, and it forms my recommendations for others engaging in the work moving forward. This recommendation is to facilitate and have the hard conversations around race white supremacy. 
Furthermore, I recommend proceeding with an explicit effort to do more anti-racist work as a food caregiver.

\subsection{Food Caregiving Moving Forward}

The work that food caregivers do is demanding and vital to human life. It deserves to be respected and valued. Women and men in these positions deserve livable wages and recognition for the efforts that keep families and communities sustained. I suggest demanding these things moving forward as food caregivers. I suggest supporting and providing in the ways you can if you are not one. So long as a patriarchal culture exists in West Virginia and beyond, both women and the work that they disproportionately perform will be devalued and often underpaid. A society and food system that actively works to eliminate gender disparities in the workplace, home, and at large is a society that begins to recognize and compensate for food caregiving labor.

The way that food caregiving proceeds forward needs modified if systemic food access barriers in a gendered and racialized food system are to be addressed. An explicitly feminist and anti-racist approach to how the labor is performed may create some substantial positive changes. Marginalized populations will not be properly served, and all voices will not be heard until leadership roles are occupied by people who are most affected by food insecurity, particularly women and people of color. To recognize whiteness and white supremacy in WV food systems is not sufficient. To not discriminate based on identity is not enough. Rather, food caregivers must proceed in their work with an explicitly anti-sexist, anti-racist, and anti-classist approach and demand it from others working alongside them.

These recommended changes apply to the reworking of existing Nourishing Networks curriculum and design as well. Though Nourishing Networks is designed to include explicit and meaningful conversations about identity, specifically gender and race, more can be done to ensure that it adopts a more inclusive, anti-racist and anti-sexist approach that incorporates the visions of food justice held by food caregivers in the state that are highlighted in this research study.

To start, additions to curriculum to include not only conversations about race and gender identity (among other identity factors) and their role in creating barriers to food, but also addressing the immense whiteness in WV food systems and community food work is crucial. 
More time needs to be spent on these matters, as they make up the foundation of the food system that the United States was built upon. Though these conversations may be uncomfortable, an explicit conversation in this environment where facilitators are present and a particular curriculum can be followed can provide a productive space for the conversations to occur.

In addition to altering and expanding the curriculum of the NN program, a shift in directorship and facilitation could be incredibly beneficial. If whiteness is indeed omnipresent in community food work and conversations around race and racism do not occur because of a largely white population according to food caregivers, then it is time to create a space for alternative visions and leadership, namely those of women of color. Women and other people of color cannot be expected to do the work of deconstructing whiteness or dismantling white supremacy in the food system - for these are structures created outside of their control, against their will, and intended directly to disenfranchise and do violence unto them. Marginalized voices of women, namely women of color, need to be uplifted and made visible by giving them a platform to be heard. However, I propose that it is the work of white people as the prominent and demographic and most privileged group in the state to provide support under the leadership and facilitation of women of color. Not only this, but it may be wise to require both diversity and inclusion as well as anti-racist training for NN workshop facilitators. This can better equip them with the skills to engage and foster productive conversations, alleviate any tensions, and provide support to others. These recommendations can be applied not only to the Nourishing Networks program, but other community food work programs and organizations that engage directly with communities.

Moving forward, new voices need to be heard, new faces need a seat at the table, and more experiences and perspectives need to be considered. This of course includes those that are absent from leadership roles and decision-making processes. Those who possess power and privilege based on race, gender, and class have a responsibility to work towards these changes which will increase equity in the work. I anticipate that food caregiving labor will continue to be implemented by predominantly women in West Virginia, nationally, and globally. However, I find that the way I grapple with this and the way in which I suggest others do as well has changed. Might we credit food caregivers, who perform this exhausting and essential labor, with the same respect and appreciation as we do other heroes who labor for the welfare of human life? I challenge you as the reader to imagine a world where the hands that feed us are as valued as 
health care professionals, scientists, or politicians. Perhaps if we as society can shift how we perceive food caregiving labor and those who perform it, credit can be given where it is due to the leaders who feed us for most of our lives. 


\section{Bibliography}

Abel, E. \& Nelson, M. 1990. Circles of Care: Work and Identity in Women's Lives. SUNY Press.

Alkon, A. \& Agyeman, J. 2011. Cultivating Food Justice: Race, Class, and Sustainability. Massachusetts Institute of Technology.

Alkon, A.; Guthman, J. 2017. The New Food Activism: Opposition, Cooperation, and Collective Action. University of California Press.

Alkon, A.H. and T.M. Mares. 2012. Food sovereignty in US food movements: radical visions and neoliberal constraints. Agriculture and Human Values 29(3):347-359.

Allen, P \& Sachs, C. 2012. Women and Food Chains: The Gendered Politics of Food. Routledge.

Allen, Theodore W. 2006. [1975]. Class Struggle and the Origin of Racial Slavery: The Invention of the White Race. Stony Brook, NY: Center for the Study of Working Class Life, SUNY, Stony Brook. OCLC 244189582. With an "Introduction" by Jeffrey B. Perry.

Baldwin, James. The Fire Next Time. 1963. The Price of the Ticket. New York: St. Martin's/Marek, 1985. 333-379.

Barbara Welter, Carl N. Degler. At Odds: Women and the Family in America from the Revolution to the Present. New York: Oxford University Press. 1980. Pp. xiv, 527. The American Historical Review, Volume 86, Issue 1, February 1981, Page 198, https://doi.org/10.1086/ahr/86.1.198.

Bellows and Hamm. 2003. U.S. Based Community Food Security: Influences, Practices, Debate. Journal for the Study of Food and Society. Vol. 6, No. 1. pp. 31-44.

Benería, L. 1997. Accounting for Women's Work: The Progress of Two Decades. Zed Books LTD.

Berheide, C. W., Chertos, C. H., \& Steinberg, R. 1987. Pay Equity for Blacks and Hispanics in New York State Government Employment. In Pay Equity: An Issue of Race, Ethnicity, and Sex. (Pg. 71-108). Washington, DC. National Committee on Pay Equity. 
Billings, D., \& Cabbil, L. 2011. Food Justice: What's Race Got to Do with It? Race/Ethnicity: Multidisciplinary Global Contexts, 5(1), 103-112. https://doi.org/10.2979/racethmulglocon.5.1.103.

Bradley, K. \& Herrera, H. 2015. Decolonizing Food Justice: Naming, Resisting, and Researching Colonizing Forces in the Movement. Antipode Vol. 0, No. 00. ISSN 0066-4812.

Broad, G. 2016. More Than Just Food: Food Justice and Community Change. University of California Press.

Brown, S., \& Getz, C. 2008. Privatizing farm worker justice: Regulating labor through voluntary certification and labeling. Geoforum, 39(3), 1184-1196. https://doi.org/10.1016/j.geoforum.2007.01.002.

Bubeck, E., \& Lecturer in Political Theory Department of Government Diemut Elisabet Bubeck. 1995. Care, Gender, and Justice. Amsterdam University Press.

Butler, J. Performative Acts and Gender Constitution: An Essay in Phenomenology and Feminist Theory (FTR 462-473).

Cancian, F. \& Oliker, S. 2000. Gender and Caring. AltaMira Press.

Cancian, F. 2000. Paid emotional care. In M. H. Meyer (Ed.),Care work: Gender, labor, and the welfare state (pp. 136-148). New York: Routledge.

Carr, E. S. 2003. Rethinking Empowerment Theory Using a Feminist Lens: The Importance of Process. Affilia, 18(1), 8-20. https://doi.org/10.1177/0886109902239092.

Carter, R. T. 2007. Racism and Psychological and Emotional Injury. The Counseling Psychologist, 35(1), 13-105. https://doi.org/10.1177/0011000006292033.

Chavez, C. 2008. Conceptualizing from the Inside: Advantages, Complications, and Demands on Insider Positionality . The Qualitative Report, 13(3), 474-494. Retrieved from https://nsuworks.nova.edu/tqr/vol13/iss3/9.

Clifford, N. J.; Valentine, G. 2003. Key Methods in Geography. London; Thousand Oaks, CA. SAGE.

Collins, P. H. 2000. Black Feminist Thought Knowledge, Consciousness, and the Politics of Empowerment. Routledge. 
Counihan, C. M. \& Kaplan, S. 2013. Food and Gender: Identity and Power. Routledge.

Counihan, C. M. 1988. Female Identity, Food, and Power in Contemporary Florence. Anthropological Quarterly, 61(2), 51. https://doi.org/10.2307/3317156.

Crenshaw, K . 1989. Demarginalizing the Intersection of Race and Sex: A Black Feminist Critique of Antidiscrimination Doctrine, Feminist Theory and Antiracist Politics. University of Chicago Legal Forum: 139-68.

Crenshaw, K. 1991. Mapping the Margins: Intersectionality, Identity Politics, and Violence against Women of Color. Stanford Law Review Vol. 43, No. 6 (pg. 1241-1299).

Creswell, J. W. 2013. Qualitative inquiry \& research design (3rd ed.). Thousand Oaks, CA: Sage.

Davis, Angela Y. 1981. Women, Race, and Class. Random House, Inc. NY.

Deere, C., et al. 1997. Impact of the Economic Crisis on Poor Women and Their Households. Zed Books LTD.

DiAngelo, R., \& Dyson, M. E. 2018. White Fragility: Why It's So Hard for White People to Talk About Racism (Reprint ed.). Beacon Press.

Dill, B. T., Cannon, L. W., \& Vanneman, R. 1987. Race and Gender in Occupational Segregation. In Pay Equity: An Issue of Race, Ethnicity, and Sex. (Pg. 11-70). Washington, DC. National Committee on Pay Equity.

Dodson, L. 2007. Wage-Poor Mothers and Moral Economy. Social Politics: International Studies in Gender, State and Society. Vol. 14, No. 2 pp. 258-280.

Du Bois, W.E.B. 1920. Darkwater: Voices from Within the Veil. New York: Washington Square Press. pp. 214. ISBN 978-0-7434-6060-6.

Duffy, M. 2011. Making Care Count: A Century of Gender, Race, and Paid Care Work. New Brunswick, New Jersey; London: Rutgers University Press.

Eaves, L. 2013. Space, place, and identity in conversation: Queer black women living in the rural U.S. South. In Sexuality/Rurality/Geography, edited by Andrew Gorman-Murray, Barbara Pini, and Lia Bryant. Lanham, MD: Lexington Books. 
England, P. 1992. Comparable Worth: Theories and Evidence. (Social institutions and social change). Aldine De Gruyter. http://www.gbv.de/dms/hbz/toc/ht004511090.PDF.

England, P. 2005. Emerging Theories of Care Work. Annual Review of Sociology. Vol. 31:38139.

Essex, J. 2012. Idle Hands are the Devil's Tools: The Geopolitics and Geo-economics of Hunger. Annals of the Association of American Geographers. Vol. 102, No. 1.

Feeding America. 2019. Retrieved from https://www.feedingamerica.org/.

Fisher, S. 1993. Fighting Back in Appalachia: Traditions of Resistance and Change. Temple University Press.

Fisher, A. 1994. What is Community Food Security? Sustainable City. http://sustainablecity.org/articles/security.htm.

Fluri, J and R Lehr. 2017. The Carpetbaggers of Kabul and Other American-Afghan Entanglements: Intimate Development, Geopolitics and the Currency of Gender and Grief. Athens, GA: University of Georgia Press.

Folbre, N. 1986. Cleaning House: New Perspectives on Households and Economic Development. Journal of Development Economics, Vol. 22, No. 1.

Frankenberg, R. 1993. White Women, Race Matters: The Social Construction of Whiteness. University of Minnesota Press. Retrieved July 1, 2020, from www.jstor.org/stable/10.5749/j.ctttsnhh.

Gibson-Graham, J.K. 1996. The End of Capitalism as we Knew it: A Feminist Critique of Political Economy. University of Minnesota Press.

Gilligan, C. 1982. In a Different Voice: Psychological Theory and Women's Development. Harvard University Press, Cambridge, Massachusetts, Pg. 24-39.

Gittell, R.; Vidal, A. 2013. Community Organizing: Building Social Capital as a Development Strategy. SAGE Publications.

Gottlieb, R. \& Joshi, A. 2010. Food Justice. Massachusetts Institute of Technology. 
Grant, K. R., et al. 2004. Caring For/Caring About Women, Home Care and Unpaid Caregiving. Garamond Press.

Guthman, J. 2008. Neoliberalism and the making of food politics in California. Geoforum, 39(3), 1171-1183. https://doi.org/10.1016/j.geoforum.2006.09.002.

Harrington Meyer, M. 2000. Care Work: Gender, Labor, and the Welfare State. Routledge.

Hartmann, H. The Unhappy Marriage of Marxism and Feminism. (FTR 187-201).

Hislop, R. 2007. Reaping Equity: A Survey of Food Justice Organizations in the U.S.A. University of California, Davis, ProQuest Dissertations Publishing, 2014.

Holloway, S. 1998. Local Childcare Cultures: Moral geographies of mothering and the social organisation of preschool education. Gender, Place and Culture: A Journal of Feminist Geography. Vol. 5, No. 1, pp. 29-53.

Holt-Giménez, E. 2015. Racism and Capitalism: Dual Challenges for the Food Movement. Journal of Agriculture, Food Systems, and Community Development, 23-25. https://doi.org/10.5304/jafscd.2015.052.014

Hondagneu-Sotelo, P. 2001. Doméstica: Immigrant workers cleaning and caring in the shadows of affluence. Berkeley, CA: University of California Press.

Hondagneu-Sotelo, P. 2001. Doméstica: Immigrant Workers Cleaning and Caring in the Shadows of Affluence. Berkeley: University of California Press.

hooks, B. 1984. Feminist Theory: From Margin to Center. South End Press.

Hooyman, N. R., Gonyea, J., Innovations, C. F. P., \& Center for Practice Innovations. 1995. Feminist perspectives on family care. SAGE Publications.

Institute for Agriculture and Trade Policy. 2019. Retrieved from https://www.iatp.org/.

International Labour Organization, 2019. Retrieved from https://www.ilo.org/global/lang-en/index.htm.

Jackson et. al. 2008. Moral Economies of Food and Geographies of Responsibility. Transactions of the Institute of British Geographers. 
James, S. M. 1993. "Mothering: A possible Black feminist link to social transformation". Routledge.

Kelly, M.; Gurr, B. 2020. Feminist Research in Practice. Rowman \& Littlefield.

Lapan, S.; Quartaroli, M.; Riemer, F. 2012. Qualitative Research: An Introduction to Methods and Designs. Wiley.

Lawson, V. 2008. Geographies of Care and Responsibility. Annals of the Association of American Geographers. Vol. 97, No. 1.

Lee, K., Zigbi, K., \& Nemes, M. 2009. Setting the Table for a Sustainable and Just Food System. The Foundation Review, 1(3), 60-75. https://doi.org/10.4087/foundationreview-d-0900033.1.

Ligrani, R. \& Niewolny, K. 2017. Community Food Work as Critical Practice: A Faith-Based Perspective through Narratives. Journal of Agriculture, Food Systems, and Community Development. Vol. 7, No. 4.

Loo, C. 2014. Towards a More Participative Definition of Food Justice. Journal of Agricultural and Environmental Ethics. 27. 10.

Makina, A. 2009. Caring for people with HIV: State policies and their dependence on women's unpaid work. Gender and Development. Vo.. 17, No. 2.

Martin, D. 2010. Constructing the 'Neighborhood Sphere': Gender and Community Organizing. Gender, Place and Culture, Vol. 9, No. 4.

McCutcheon, P. 2015. Food, Faith and the everyday struggle for black urban community. Social and Cultural Geography. Vol. 16, No. 4, pp. 385-406.

McCutcheon, P. 2019. Fannie Lou Hamer's Freedom Farms and Black Agrarian Geographies. Antipode, 51(1), 207-224. https://doi.org/10.1111/anti.12500.

McMichael, P. 2009. A Food Regime Genealogy. Journal of Peasant Studies. Vol 36, No. 1. pp. 139-169.

Merriam, S.; Tisdell, E. 2015. Qualitative Research: A Guide to Design and Implementation. John Wiley \& Sons, Incorporated. 
Meyer, M., Herd, P., \& Michel, P. 2000. Care Work: Gender, Class, and the Welfare State. Routledge.

Mikula, G. 2005. Some Observations and Critical Thoughts About the Present State of Justice Theory in Research.

Milkman, R. 1998. The Macrosociology of Paid Domestic Labor. Work and Occupations Vol. 25, No. 4.

Misra, J. 2003. The Intersection of Gender and Race in the Labor Market. Annual Review of Sociology. Vol. 29:487-513.

Mitchell, K.; Marston, A.; Katz, C. 2004. Life's Work: Geographies of Social Reproduction. Blackwell Publishing.

Moen, P.; Robison, J.; Fields, V. 1994. Women's Work and Caregiving Roles: A Life Course Approach. Journal of Gerontology, Vol. 49, No. 4.

Mohai, P., Lantz, P. M., Morenoff, J., House, J. S., \& P. Mero, R. P. 2009. Racial and Socioeconomic Disparities in Residential Proximity to Polluting Industrial Facilities: Evidence from the Americans' Changing Lives Study. American Journal of Public Health Vol. 99, No. S3.

Morales, A. 2011. Growing food and justice: dismantling racism through sustainable food systems. In Alkon A.H. and J. Ageyman (eds.) Cultivating food justice: race, class and sustainability. Cambridge: MIT Press. Pp.149-176.

Morrison, T. 1992. Playing in the Dark: Whiteness and the Literary Imagination. Harvard University Press.

N Götz. 2015. 'Moral economy': its conceptual history and analytical prospects. Journal of Global Ethics. Vol. 11, No. 2.

Nagar, R. 2014. Muddying the Waters: Co-Authoring Feminisms across Scholarship and Activism. University of Illinois Press.

Nakano Glenn, E. 1992. "From Servitude to Service Work: Historical Continuities in the Racial Division of Paid Reproductive Labor," Signs: Journal of Women in Culture and Society. 
Naples, N. 1998. Community Activism and Feminist Politics: Organizing Across Race, Class, and Gender. Routledge.

Naples, N. 1998. Grassroots Warriors: Activist Mothering, Community Work, and the War on Poverty. Routledge.

National Conference of State Legislatures. 2019. Retrieved from http://www.ncsl.org/.

Norgaard, K. M., R. Reed, and C. Van Horn. 2011. A continuing legacy, institutional racism, hunger and nutritional justice on the Klamath. In Alkon A.H. and J. Ageyman (eds.) Cultivating food justice: race, class and sustainability. Cambridge: MIT Press. Pp23-46.

Passidomo, C. 2013. Going "Beyond Food": Confronting Structures of Injustice in Food Systems Research and Praxis. Journal of Agriculture, Food Systems, and Community Development, 1-5. https://doi.org/10.5304/jafscd.2013.034.009.

Patel, R. C. 2012. Food Sovereignty: Power, Gender, and the Right to Food. PLOS Medicine.

Poppendieck, J. 1998. Sweet Charity? Emergency Food and the End of Entitlement. Penguin Books: New York.

Pratt, G. 2012. Families Apart: Migrant Mothers and the Conflicts of Labour and Love. Minneapolis: University of Minnesota Press.

Ramírez, M. M. 2015. The elusive inclusive: Black food geographies and racialized food spaces. Antipode, 47(3), 748-769.

Rappaport, J., Swift, C. F., \& Hess, R. 1984. Studies in Empowerment. Amsterdam University Press.

Reese, A. M. 2019. Black Food Geographies. Amsterdam University Press.

Reid, L. L. 1998. Devaluing Women and Minorities: The Effects of Race/Ethnic and Sex Composition of Occupations on Wage Levels. Work and Occupations. Vol. 25, No. 4.

Remick, H., Ginorio, A. B., \& Britz, P.1987. A Case Study in Washington State. In Pay Equity: An Issue of Race, Ethnicity, and Sex. (Pg. 109-149). Washington, DC. National Committee on Pay Equity.

Rinaldo Seitz, V. 1998. Class, Gender, and Resistance in the Appalachian Coalfields. Routledge. 
Romero, M. 1992. Maid in the U.S.A. New York: Routledge.

Ross, J. 1987. Race and Sex Discrimination in Los Angeles County Employment Policies. In Pay Equity: An Issue of Race, Ethnicity, and Sex. (Pg. 150-173). Washington, DC. National Committee on Pay Equity.

Sbicca, J. 2012. Book Review: Cultivating Food Justice: Race, Class, and Sustainability. Organization \& Environment, 25(2), 206-208. https://doi.org/10.1177/1086026612449745.

Sbicca, J. 2012. Growing food justice by planting an anti-oppression foundation: opportunities and obstacles for a budding social movement. Agriculture and Human Values, 29(4), 455-466. https://doi.org/10.1007/s10460-012-9363-0.

Sbicca, J. 2018. Food Justice Now! Deepening the Roots of Social Struggle. University of Minnesota Press.

Sceats, S. 1996. Eating the evidence: women, power and food. In: Sceats, Sarah and Cunningham, Gail, (eds.) Image and power: women in fiction in the twentieth century. Harlow, U.K. : Longman. pp. 117-127. ISBN 0582255368.

Schram, T. H. 2003. Conceptualizing qualitative inquiry. Upper Saddle River, NJ: Merrill Prentice Hall.

Slocum, R. (2006). Anti-racist Practice and the Work of Community Food Organizations. Antipode, 38(2), 327-349. https://doi.org/10.1111/j.1467-8330.2006.00582.x.

Slocum, R. 2007. Whiteness, space and alternative food practice. Geoforum, 38(3), 520-533. https://doi.org/10.1016/j.geoforum.2006.10.006.

Slocum, R., \& Saldanha, A. 2016. Geographies of Race and Food: Fields, Bodies, Markets (Critical Food Studies) (1st ed.). Routledge.

Spatig, L., et al. 2001. We Roll Deep: Community and Resistance in the Lives of Appalachian Girls. Journal of Appalachian Studies, Vol. 7, No. 1.

Thompson, E. P. 1971. "The Moral Economy of the English Crowd in the 18th Century". Past \& Present. 50: 76-136. 
Tomaskovic-Devey, D. 1993. Gender and Racial Inequality at Work: The Sources and Consequences of Job Segregation. Ithaca, NY: ILR Press.

Tronto, J. 1993. Moral Boundaries: A Political Argument for an Ethic of Caring. New York: Routledge.

United States Department of Agriculture. 2019. Retrieved from https://www.usda.gov/.

Vernon, J. 2007. Hunger: A Modern History. Harvard University Press.

White, M. M., \& Redmond, L. D. 2018. Freedom Farmers. Amsterdam University Press.

Wilkerson, J. 2019. To Live Here, You Have to Fight: How Women Led Appalachian Movements for Social Justice. University of Illinois Press.

Williams, M.; Moser, T. 2019. The Art of Coding and Thematic Exploration in Qualitative Research. International Management Review; Marietta Vol. 15, No. 1.

Wilson, B. et al. 2016. Nourishing Networks: West Virginia Food Security Assessment. http://foodlink.wvu.edu/ 


\section{Appendix A - Semi-Structured Interview Questions}

Interview Questions:

1. May I record this interview?

2. Would you like to remain anonymous or use a pseudonym for this interview considering your responses may be used in my written thesis and in presentations to the public?

3. Which gender identity would you most identify with?

4. What racial identity do you most identify with?

5. Are you from WV originally?

6. What is your job position and/or what work do you do in West Virginia?

7. Describe the community(ies) in which your work.

8. What inspired you to get involved in this work?

9. What motivates you to continue this work?

10. What role does morality and ethics take in your choice to do this work?

11. How would you describe the relationship between the work that you do and care work?

12. How do you provide care in your community?

13. How would you describe the role that your identity (gender, race, age, class, ability, etc.) plays in how you interact with your community and how your community interacts with you?

14. Would you characterize your work as food justice? Why or why not?

15. Would you describe your work to have short term, medium term, and/or long term outcomes? Why?

16. What inequalities have you witnessed by being involved in West Virginia food systems?

17. What needs to be considered in strategizing toward long term food system change? 
18. Why do you think a need exists for charitable food and government assistance/feeding programs in West Virginia?

19. What are some structural or systemic problems you identify in WV food systems through your work?

20. Why do you think the majority of food caregiving work is performed by women in West Virginia?

21. Do societal expectations associated with part of your identity affect your work? If so, how?

22. Do you think race and racism shape food access? Do you find this to be difficult to talk about within your organization? Why or why not?

23. West Virginia as a state has a largely white population. How would you describe the presence and role of whiteness in community food work in WV?

24. Do you think we adequately address racism in our food system? How do you think we can address racism in our food system as food caregivers and otherwise? 


\section{Appendix B - Initial Interview Codes}

- Emotional Aspects of the Work

- Empowerment and Power

- Going Above and Beyond

- Sacrifice

- Listening and Conversation

- Relationships, Community, and Networks

- Women Possessing Advanced Skills in Patience, Listening, and Identifying Context Clues

- Race-based Trauma and the Need to Heal and be Support

- Pain and Discomfort Necessary to Create Change

- Change takes Time

- Smaller Goals and Outcomes lead to Longer Term Ones

- The Right People Aren't in the Room when Strategizing and Organizing Happens

- People are Stripped From and Prevented From Accessing Knowledge

- This Means More than "Just a Job" for Most Food Caregivers

- Individual and Systemic Problems are Internalized and Normalized

- White People Need to Step Up - They Have a Job to do to Eliminate Whiteness and Racism in the Food System

- Women Are the Perhaps the Only Ones Who Can do this Work

- Racism Needs Acknowledged and Discussed

- Patriarchal "Traditional" WV Culture

- Lack of Opportunities in WV

- Many Began in Other Related Work and Noted a Need or Gap that Needed Addressed

- Pollution and Extractive Legacies in WV Contribute to Food Security and Sovereignty Barriers

- Women are Expected to do this Work 


\section{Appendix C - Participant Race and Occupation}

\begin{tabular}{|c|c|c|}
\hline Participant & Racial Identity & $\begin{array}{l}\text { Food System Sector/Work } \\
\text { Focus }\end{array}$ \\
\hline Participant 1 & White & Advocacy/Organizing \\
\hline Participant 2 & White & $\begin{array}{l}\text { Public Health/University } \\
\text { Extension Education }\end{array}$ \\
\hline Participant 3 & White & $\begin{array}{l}\text { Charitable Food - Food } \\
\text { Pantry }\end{array}$ \\
\hline Participant 4 & White & $\begin{array}{l}\text { University Extension } \\
\text { Education }\end{array}$ \\
\hline Participant 5 & African American & Community Development \\
\hline Participant 6 & White & Agriculture/Policy \\
\hline Participant 7 & White & Agriculture/Policy \\
\hline Participant 8 & White & Agriculture - Producer \\
\hline Participant 9 & White & Charitable Food - Food Bank \\
\hline Participant 10 & Black & Organizing/Policy \\
\hline Participant 11 & Black & Policy/Organizing/Education \\
\hline Participant 12 & White & Education/Research \\
\hline Participant 13 & $\begin{array}{l}\text { Biracial - South } \\
\text { Asian/Hispanic }\end{array}$ & $\begin{array}{l}\text { Education/Public } \\
\text { Health/Research }\end{array}$ \\
\hline
\end{tabular}

